\title{
Comparison of the effects of open vs. closed skill exercise on the acute and chronic BDNF, IGF-1 and IL-6 response in older healthy adults
}

Tom Behrendt ${ }^{*+}$ (0), Franziska Kirschnick ${ }^{2 \dagger}$, Lasse Kröger ${ }^{1}$, Phillip Beileke ${ }^{1}$, Maxim Rezepin ${ }^{1}$, Tanja Brigadski ${ }^{3}$, Volkmar Leßmann ${ }^{4,5}$ and Lutz Schega ${ }^{1}$

\begin{abstract}
Background: Accumulating evidence shows that physical exercise has a positive effect on the release of neurotrophic factors and myokines. However, evidence regarding the optimal type of physical exercise for these release is still lacking. The aim of this study was to assess the acute and chronic effects of open-skill exercise (OSE) compared to closed-skill exercise (CSE) on serum and plasma levels of brain derived neurotrophic factor $\left(\mathrm{BDNF}_{\mathrm{S}}, \mathrm{BDNF}_{\mathrm{p}}\right)$, and serum levels of insulin like growth factor 1 (IGF-1), and interleukin 6 (IL-6) in healthy older adults.
\end{abstract}

Methods: To investigate acute effects, thirty-eight participants were randomly assigned to either an intervention (badminton (aOSE) and bicycling (aCSE), $n=24,65.83 \pm 5.98$ years) or control group (reading (CG), $n=14$, $67.07 \pm 2.37$ years). Blood samples were taken immediately before and $5 \mathrm{~min}$ after each condition. During each condition, heart rate was monitored. The mean heart rate of aOSE and aCSE were equivalent ( $65 \pm 5 \%$ of heart rate reserve). In a subsequent 12 -week training-intervention, twenty-two participants were randomly assigned to either a sport-games (COSE, $n=6,64.50 \pm 6.32$ ) or a strength-endurance training (CCSE, $n=9,64.89 \pm 3.51$ ) group to assess for chronic effects. Training intensity for both groups was adjusted to a subjective perceived exertion using the CR-10 scale (value 7). Blood samples were taken within one day after the training-intervention.

Results: $B D N F_{s}, B D N F_{p}, I G F-1$, and IL-6 levels increased after a single exercise session of 30 min. After 12 weeks of training $\mathrm{BDNF}_{\mathrm{S}}$ and IL-6 levels were elevated, whereas IGF-1 levels were reduced in both groups. However, only in the cOSE group these changes were significant. We could not find any significant differences between the exercise types.

Conclusion: Our results indicate that both exercise types are efficient to acutely increase BDNF BDNFF, $_{\mathrm{p}}$ IGF-1 and IL-6 serum levels in healthy older adults. Additionally, our results tend to support that OSE is more effective for improving basal BDNF levels after 12 weeks of training.

Keywords: Open skill exercise, Closed skill exercise, Brain-derived neurotrophic factor (BDNF), Insulin-like growth factor 1 (IGF-1), Interleukin-6 (IL-6), Aging

${ }^{\dagger}$ Tom Behrendt and Franziska Kirschnick have contributed equally to this manuscript and share the first authorship

*Correspondence: tom.behrendt@ovgu.de

${ }^{1}$ Chair for Health and Physical Activity, Department of Sport Science, Faculty of Humanities, Otto-von-Guericke University Magdeburg, Magdeburg, Germany

Full list of author information is available at the end of the article

\section{Background}

Aging is associated with changes in brain structure and function [1-4] and in turn, with an increased risk of developing cognitive impairments and neurodegenerative diseases (e.g., dementia) [5-7]. In this context, it has been shown that physical exercise (defined as a specific, planned and structured form of physical activity, which 
leads to acute (transient) effects [8-10]) and/or physical training (defined as repeated bouts of physical exercise, which leads to chronic (long-term) effects $[8,10]$ ) could be an appropriate approach to maintain or enhance physiological brain functions, thereby helping to prevent neurodegenerative diseases in the elderly population [11-19].

Although the exact underlying neurobiological mechanisms are not yet fully understood, it is assumed that the beneficial effects of physical exercise and/or physical training on cognition are based on effects that can be observed at multiple levels (i.e., molecular and cellular changes, structural and functional changes, socioemotional changes) [20-22]. At the molecular level, different neurotrophic factors and myokines like brain-derived neurotrophic factor (BDNF), insulin-like growth factor 1 (IGF-1), and interleukin-6 (IL-6) are currently described as possible key factors that are up-regulated and released in response to acute physical exercise [23-29]. According to the "neurotrophic hypotheses" [30, 31], in long-term the exercise-related release of neurotrophic factors can promote functional and structural brain changes, that in turn might contribute to the maintenance or increase of cognitive functions [32,33]. In this regard, it has been shown that BDNF promotes various processes of neuroplasticity, such as neurogenesis, neuronal differentiation, synaptogenesis and neuronal protection [34-36]. Furthermore, BDNF is crucially involved in processes of synaptic plasticity like long-term potentiation throughout the brain and thus regulates memory formation and learning processes [37-41]. Along these lines, higher serum levels of BDNF are positively associated with increased hippocampal volume in humans [42]. There is also evidence that an increase in IGF-1 improves neurogenesis [43-45], the maintenance and reshaping of brain vessels (angiogenesis), as well as the survival of neurons [46]. With regard to neurocognitive changes, IL-6 is involved in the homeostatic control of memory mechanisms and neurophysiological processes in the brain [47] and stimulates the production of anti-inflammatory cytokines such as IL-1ra and IL-10 [48]. However, current evidence suggests that the expression of neuroproteins and/or myokines (e.g.,, BDNF, IGF-1, IL-6) depends on exercise variables (e.g.,, exercise intensity, exercise duration, type of physical exercise) and/or training variables (e.g.,, frequency, density, duration) and training principles (e.g.,, progression, specificity, reversibility) [16, 49-52].

With regard to the type of physical exercises, there exist various classification approaches in the literature. Exercise types can be classified based on the predictability of the performing environment and the exercise complexity (motor and/or cognitive demands) [53, 54].
According to this differentiation, exercise types can be classified into (i) open skill exercise (OSE) and (ii) closed skill exercise (CSE). OSE (e.g., badminton, table tennis) are performed in dynamic, externally-paced, and more unpredictable environments, while CSE (e.g., running, bicycling) includes relatively consistent, self-adjustable and more predictable environments [50]. A recent review by $\mathrm{Gu}$ et al. [50] that compared the effects of OSE versus CSE on cognitive functions, showed that OSE led to greater improvements in cognitive functions in both children and older adults. However, the majority of the studies in this review were observational studies. So it is not clear whether OSE is more beneficial to brain health than CSE or whether people with better status of cognitive functions prefer this type of exercise. These results are confirmed by the meta-analysis of Zhu et al. [55]. The authors show that, compared with CSE, OSE is more advantageous in improving cognitive functions, especially with respect to executive functions such as inhibition and cognitive flexibility. However, only 4 out of 19 studies included in this meta-analysis were intervention studies. Excluding the cross-sectional studies, no significant differences could be found between the two exercise types [55]. In this context, Hung et al. [56] investigated the acute effect of OSE and CSE on the BDNF concentration in the blood of young males. The results of this study showed that OSE (badminton) leads to a stronger BDNF release than CSE (running). However, the observed acute effects found in the study of Hung et al. [56] cannot be transferred to chronic effects or other cohorts, e.g., older people.

To further investigate the acute and chronic effects of OSE versus CSE on the release of neurotrophic proteins and myokines, we compared the exercise and training related changes in blood levels of BDNF, IGF-1 and IL-6 in response to the two different types of exercise in healthy older adults.

\section{Methods Study design}

The present study consisted of two investigations with different study designs (see Figs. 1, 2) to determine the (i) acute effects (after a single exercise session) and (ii) chronic effects (after a training period consisting of several acute exercise sessions) of two different exercise types (OSE vs. CSE) on the blood levels of BDNF (plasma and serum), IGF-1, and IL- 6 . To assess acute exerciserelated effects, we used a 3 group $\times 2$ time points (pre and post exercise) cross-over design. Following the first investigation, a 12 week-long training intervention study with a 2 group $\times 2$ time (pre and post training intervention) parallel group design was conducted between April and June 2019 to determine the chronic effects. The 




group allocation in both groups was randomized. Due to the nature of physical exercise interventions, it was not possible to blind the participants and the trainers. Outcome assessors including the medical doctor who took the blood samples and the laboratorian who analysed the blood samples for BDNF, IGF-1 and IL-6 concentration were blinded because they had no knowledge of the subjects' group allocation. The study is in accordance with the principles stated in the declaration of Helsinki and was reviewed and approved by the board of the ethical committee of the Otto-von-Guericke University Magdeburg (29/19).

To investigate acute effects three separate appointments were carried out. At the first appointment, the participants were informed about the aim, purpose and procedure of the study and gave their written informed 


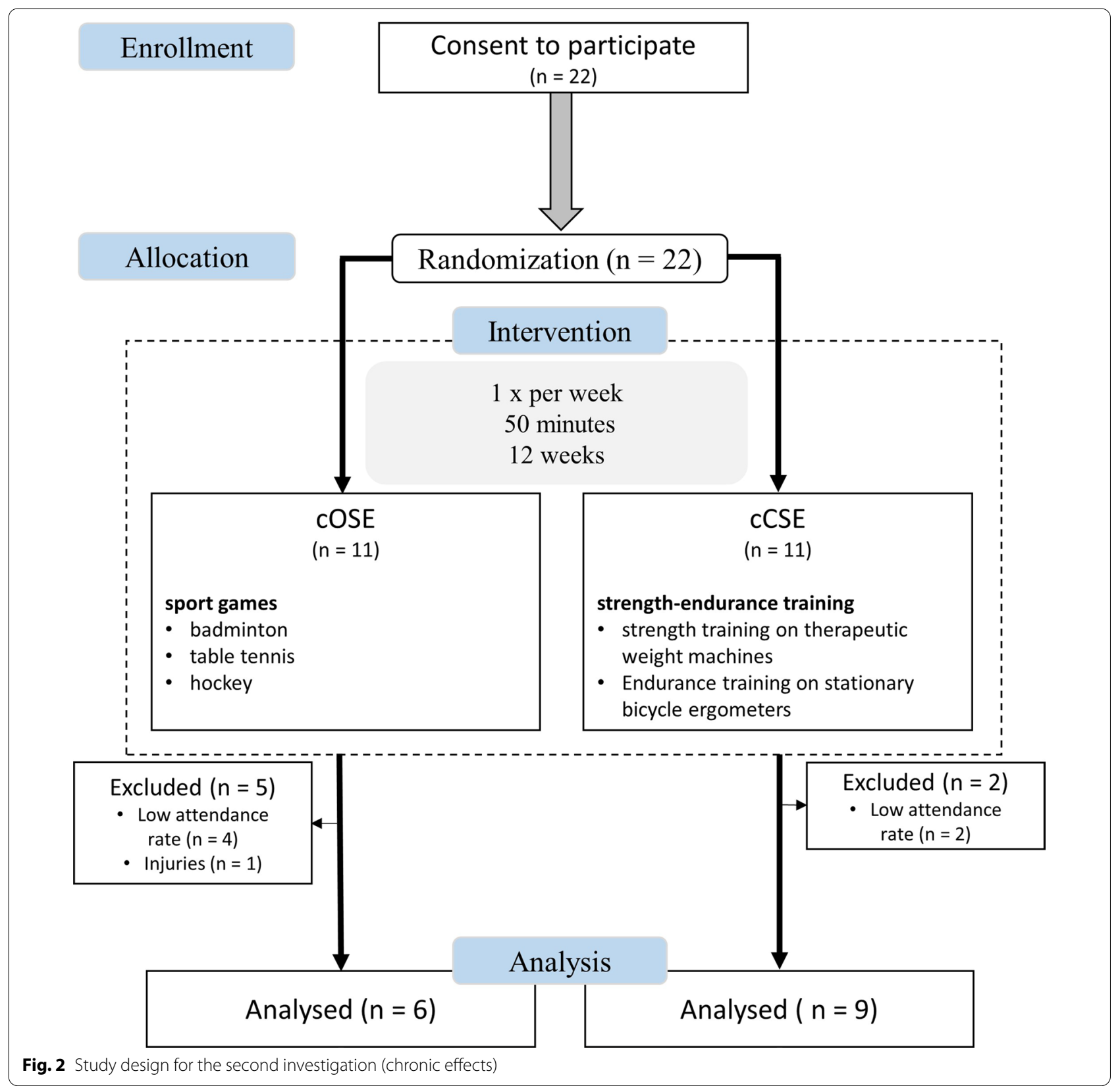

consent for voluntary participation. After consent was obtained, body height and body mass were measured using a standard stadiometer (Seca, Switzerland). Thereafter, the participants' physical activity and mental status were determined using the German questionnaire "Freiburger Fragebogen zur körperlichen Aktivität" (FFkA) [57] and the Mini-Mental State Examination (MMSE) [58], respectively. The FFkA determined the health related activity including basic activity, extracurricular activity and activity in sports retrospective for 1 week (in hours per week). Following this, participants lay down in a quiet room for 15 min while the heart rate was measured using a heart rate monitor (RS800cx, Polar, Finland). The resting heart rate was defined as the mean value of the last $5 \mathrm{~min}$. Participants were then randomly assigned in either an intervention group or a control group. After screening, participants from the intervention group individually attended to the laboratory for two exercise sessions (OSE and CSE session) with a 7-day interval between sessions. The order in which the participants either performed the OSE or the CSE session was randomized and counterbalanced. The control group 
visited the laboratory for only one additional measurement appointment. Thus, the first investigation (assessing the acute effects) consists of three groups: (i) acute OSE (aOSE), (ii) acute CSE (aCSE) and (iii) control group (CG). After the first investigation had been completed, we conducted a 12-week training intervention to compare the chronic effects of OSE versus CSE. There were at least 8 days between the last acute exercise session of the first investigation and the first training session of the second investigation. Therefore, we designed two active groups: (i) chronic OSE (cOSE) and (ii) chronic CSE (cCSE) without an inactive control group.

\section{Participants}

Forty healthy elderly volunteers aged $55-75$ years were recruited by a newsletter announcement and screened for their eligibility to participate. Exclusion criteria were defined as follows: participating in any regular exercise program, cognitive impairments as detected by the MMSE, any history of several cardiovascular or metabolic diseases, and reduced and uncorrected vision. Thirty-nine participants met the inclusion criteria and were included in our study.

Regarding the first investigation assessing the acute effects of a single exercise session, 25 of the remaining participants were assigned to the intervention group and 14 participants were assigned to the control group. One participant from the intervention group left the study due to time constrains. Finally, data sets of 38 participants (24 from the intervention group and 14 from the control group) were analysed (see Fig. 1). The participants' characteristics of both groups are presented in Table 1.

Following the first investigation, 22 participants from the intervention group and the control group voluntarily agreed to participate in the long-term intervention study to assess chronical effects. Participants were randomly allocated to either the cCSE group or the cOSE group. After 12 weeks of training, we were able to evaluate the data of 15 participants (6 from the cOSE group and 9 from the cCSE group). Seven participants had to be excluded due to injuries (cOSE group: $\mathrm{n}=1$ ) and insufficient attendance rates (cCSE group: $\mathrm{n}=4$, cOSE group: $\mathrm{n}=2$ ). The anthropometric characteristics (age, weight, height, and body mass index) of the remaining participants are depicted in Table 2.

\section{Procedure}

\section{First investigation: acute effects}

The procedure for the first investigation is depicted in Fig. 1. Participants from the intervention group were instructed to perform either a single/acute OSE session (aOSE group, badminton) or a single/acute CSE session (aCSE group, bicycling) (i.e., participants who
Table 1 Characteristics on the participants of the active intervention group (aOSE and aCSE) and the inactive control group (CG) at baseline

\begin{tabular}{lll}
\hline Group N (female/male) & $\begin{array}{l}\text { Intervention } \\
\text { Group 24 (12/12) }\end{array}$ & CG 14 (6/8) \\
Measure & M (SD) & M (SD) \\
\hline Age (years) & $65.83(5.98)$ & $67.07(2.37)$ \\
$\quad<65$ years [N (\%)] & $9(37.5 \%)$ & $2(14.3 \%)$ \\
$\geq 65$ years [N (\%)] & $15(62.5 \%)$ & $12(85.7 \%)$ \\
Weight (kg) & $84.05(16.51)$ & $76.84(12.69)$ \\
Height (m) & $1.73(0.10)$ & $1.68(0.08)$ \\
BMI (kg/m $\left.{ }^{2}\right)$ & $28.08(4.37)$ & $27.24(4.41)$ \\
kcal/week & $2047.23(1674.41)$ & $2313.03(2118.45)$ \\
Resting HR (bpm) & $68.25(9.50)$ & $70.00(9.00)$ \\
Educational achievement (N) & & \\
$\quad$ Secondary education & $7(29.2 \%)$ & $6(42.9 \%)$ \\
High school & $5(20.8 \%)$ & $2(14.3 \%)$ \\
$\quad$ University & $10(41.7 \%)$ & $3(21.4 \%)$ \\
$\quad$ Academic degree & $2(8.3 \%)$ & $3(21.4 \%)$ \\
MMSE & $28.8(1.2)$ & $29.1(0.9)$ \\
\hline
\end{tabular}

$B M I$ body mass index; $H R$ heart rate

Table 2 Characteristics on the participants of the cOSE group and the cCSE group at baseline

\begin{tabular}{lll}
\hline $\begin{array}{l}\text { Group N (female/male) } \\
\text { Measure }\end{array}$ & cOSE 6 (4/2) & cCSE 9 (6/3) \\
M (SD) & M (SD) \\
\hline Age (years) & $64.50(6.32)$ & $64.89(3.51)$ \\
$\quad<65$ years [N (\%)] & $2(33.3 \%)$ & $4(44.4 \%)$ \\
$\geq 65$ years [N (\%)] & $4(66.7 \%)$ & $5(55 . \%)$ \\
Weight (kg) & $76.05(11.52)$ & $86.02(28.68)^{*}$ \\
Height (m) & $1.66(0.05)$ & $1.73(0.05)$ \\
BMI (kg/m $\left.{ }^{2}\right)$ & $27.58(4.48)$ & $28.68(5.28)$ \\
kcal/week & $2407.28(1973.127)$ & $1073.10(670.21)$ \\
Resting HR (bpm) & $67.67(5.57)$ & $67.56(10.48)$ \\
Educational achievement (N) & & \\
$\quad$ Secondary education & $3(50.0 \%)$ & $2(22.2 \%)$ \\
High school & $1(16.7 \%)$ & $1(11.1 \%)$ \\
$\quad$ University & $2(33.3 \%)$ & $4(44.4 \%)$ \\
$\quad$ Academic degree & $0(0.0 \%)$ & $2(22.2 \%)$ \\
MMSE & $28.7(1.8)$ & $29.0(0.9)$
\end{tabular}

$B M /$ body mass index

Asterisk indicate significant difference between groups $\left({ }^{*} 0.050>p \geq 0.001\right)$

started with the OSE session as the first intervention performed the CSE session during the second measurement appointment and vice versa). Both exercise sessions consisted of an identical 5-min warm up, followed by $30 \mathrm{~min}$ of the main exercise (badminton or bicycling) and an identical 5-min cool down. During the exercise 
sessions, heart rate was continuously recorded and controlled using a heart rate monitor (RS800cx, Polar, Finland). In the aOSE group (badminton session), the participants played individually against one of the two experienced instructors (i.e., 1 versus 1 ) without any breaks (e.g., for changeover). Scores were not recorded and no match-winner was determined. The single session of the aCSE group (bicycling session) was performed on a stationary bicycle ergometer (Kardiomed, Proxomed ${ }^{\circledR}$, Germany) at a cadence of 70-80 revolutions per minute. The average session intensity was set to $60 \pm 5 \%$ of each participant's individual heart rate reserve (HRR). The HRR was defined as the difference between the maximum heart rate $\left(\mathrm{HR}_{\max }\right)$ and the resting heart rate $\left(H R_{\text {rest }}\right)\left(\mathrm{HRR}=\mathrm{HR}_{\max }-\mathrm{HR}_{\text {rest }}\right)$. The $\mathrm{HR}_{\max }$ is calculated using the formula $H R_{\max }=205.8-0.685 \times$ age [59]. The target heart rate for the exercise sessions was calculated using the Karvonen formula targetheartrate $=(H R R \times 60 \%)+H R_{\text {rest }}$ [60]. Participants from the CG rested in a sitting position for $40 \mathrm{~min}$ in a quiet room and were asked to read in a magazine with sport science topics.

Blood samples were obtained at two time points: immediately before (T1) and $5 \mathrm{~min}$ after (T2) the respective test condition (badminton, bicycling or reading). Furthermore, ratings of perceived exertion (RPE) measures were obtained at rest and immediately after completing the respective test condition using the RPE-scale, which ranges from 6 to 20 with 6 for minimal effort and 20 for maximal effort [61]. In addition, for both, the aOSE and aCSE group, an end-to-end capillary of $10 \mu \mathrm{l}$ of capillary blood was taken from the right hyperemic earlobe before and after exercising to determine the blood lactate concentration.

\section{Second investigation: chronic effects}

The procedure for the second investigation is depicted in Fig. 2. The training sessions of the cCSE group as well as the cOSE group took place once a week, lasting $50 \mathrm{~min}$ per session ( 5 min warm up, followed by $40 \mathrm{~min}$ of the main exercise and $5 \mathrm{~min}$ cool down), and were provided for 12 weeks. All training sessions were conducted by a sports coach who demonstrated the exercises.

The cOSE group practiced different sport games such as badminton, hockey and table tennis with a focus on learning specific techniques and variants of the respective sport game. In each individual session the participants either learned a new technique or were confronted with a new variation of the game.

The main part of the training sessions of the CCSE group consisted of two exercise blocks: (i) strength training and (ii) endurance training. Each exercise block lasted $20 \mathrm{~min}$. The strength training involved exercises comprised alternating movements (e.g., leg-press, legextension, leg-flexion, pull-down, rowing, chest-press, triceps-press, butterfly, upper body-flexion, upper bodyextension, upper body-rotation) and was performed at therapeutic weight machines (compass 530, Proxomed ${ }^{\circledR}$, Germany) with predicted motion range and direction to keep the coordinative requirements as low as possible. The intensity of the resistance training was determined by the following variables: number of exercises per unit: 4; sets per exercise: 3 ; repetitions per set: 15 ; repetition velocity: $2-0-2-0$ ( $2 \mathrm{~s}$ concentric, $0 \mathrm{~s}$ isometric, $2 \mathrm{~s}$ eccentric, $0 \mathrm{~s}$ isometric; time under tension: $60 \mathrm{~s}$ ); interset rest period: $30 \mathrm{~s}$; inter-exercise rest period: $2 \mathrm{~min}$. The endurance training was performed on stationary bicycle ergometers with a cadence between 70 and 80 revolutions per minute. Compared to our first investigation (acute effects), we changed our approach to define exercise intensity because of methodological reasons (e.g., number of people exercising at the same time and exercise mode). For the second investigation (chronic effects), the intensity of the training was controlled and adjusted by an inductive approach using the Category Ratio- 10 Scale (CR-10 Scale) [62]. Participants were asked to rate their perceived exertion following each exercise (including the endurance training). The target intensity was defined as "very strong" (7 on the CR-10 Scale). If the participants indicated values above or below the target intensity, the training load was adjusted by the trainer for the next training session. The participants were not informed about the target intensity so that they would not be influenced in their subjective perception.

Blood samples were taken within one day after (T3) the intervention to quantify basal changes (from T1 to T3).

\section{Blood sampling}

Venous blood samples were taken by a medical doctor at the above mentioned time points (T1, T2 and T3) from the median cubital vein or the cephalic vein. The procedure of the blood collection was identical for all participants and was performed by the same persons. The blood samples were collected in two vacutainers with separating gel and coagulation activator (BD Vacutainer ${ }^{\circledR}$ $\mathrm{SST}^{\mathrm{TM}}$ II Advance, green, $8.5 \mathrm{ml}$ ) and one vacutainer with li-heparin (BD Vacutainer ${ }^{\circledR}$ LiHeparin, yellow, $4.0 \mathrm{ml}$ ). The vacutainer with li-heparin was used to determine the plasma level of BDNF. The vacutainers with separating gel and coagulation activator were used to analyze the serum levels of BDNF, IGF-1 and IL-6. Immediately after blood collection, blood samples were swirled head down for ten times. Thereafter, the serum samples were rested for $30 \mathrm{~min}$ at room temperature whereas the plasma sample rested for $10 \mathrm{~min}$ on ice. All blood samples were centrifuged at $2000 \mathrm{~g}$ for $15 \mathrm{~min}$. $300 \mu \mathrm{l}$ of the supernatant 
fluid were then extracted and stored at $-80{ }^{\circ} \mathrm{C}$. To analyzed the serum and plasma concentration of BDNF we used the BDNF DuoSet ELISA kit (R\&D Systems ${ }^{\circledR}$, Wiesbaden, Germany). Serum IL-6 and IGF-2 levels were quantified using a chemiluminescent immunometric assay (for IL6: IMMULITE ${ }^{\circledR}$ 2000; Siemens Medical Solution Diagnostics, for IGF-1: IDS-iSYS; Immunodiagnostic Systems). The samples were processed accordingly to the kit instructions.

\section{Statistical analysis}

Data were tested for normal distribution and homogeneity of variance using the Kolmogorov-Smirnov-Test and Levene's test, respectively. For normally distributed data, a 2 (time: pre-test, post-test) $\times 3$ (group: aOSE, aCSE, CG) repeated-measures ANOVA was used to check for interaction effects and main effects (main group effect and main time effect). To identify differences between groups during a measurement time point (group effect), we performed post hoc $t$ test. If significant main time effects were detected, a one-way ANOVA with repeated measures was performed to identify time effects within the groups. The post-hoc tests were adjusted by Bonferroni correction [63]. To clarify the practical relevance of the results, the effect size partial eta squared $\left(\eta_{\mathrm{p}}{ }^{2}\right)$ were reported [64]. Group differences in age, weight, height, BMI, physical activity level, and resting HR were analyzed using an independent $t$ test. For not normally distributed data, differences between measurement time points within a group (time effect) and differences between groups within a measurement time point (group effect) were analyzed with a Wilcoxon-test and Mann-Whitney $U$ test, respectively. For statistically significant results, the effect size for these non-parametric tests were calculated using the formula: $r=|z| / \sqrt{n}$ with $\mathrm{r} \geq 0.5$ rates a large effect, $0.5<\mathrm{r} \geq 0.3$ rates a medium effect and $0.3<\mathrm{r}$ $\geq 0.1$ rates a small effect. All statistical analyses were calculated with SPSS Statistics 25 (IBM, Inc., Chicago). The level of significance was set to $\alpha=0.050$.

\section{Results}

\section{Acute effects}

At baseline, no differences in age, weight, height, body mass index, activity level, and resting heart rate were observed between the active intervention group (aOSE and aCSE) and the inactive control group. Results also showed no differences for the average exercise heart rate between aOSE $(129.21 \pm 12.96 \mathrm{bpm})$ and aCSE $(124.50 \pm 7.15 \mathrm{bpm})$. For RPE, no differences between groups were found at pre-test (aOSE: 9.0 \pm 3.5 ; aCSE: 9.0 \pm 2.3 ; CG: $9.0 \pm 2.0$ ). Significant time effects were observed for the aOSE $(\mathrm{Z}=4.212, \mathrm{p}<0.001 ; 14.0 \pm 2.0)$ and aCSE group $(\mathrm{Z}=4.217, \mathrm{p}<0.001 ; 13.0 \pm 2.0)$, indicating that participants had higher RPE values after exercising. In the post-test, significantly higher RPE values were found for the aOSE $(\mathrm{Z}=-4.150, \mathrm{p}<0.001)$ and aCSE group $(\mathrm{Z}=-4.076, \mathrm{p}<0.001)$ in comparison to the inactive CG $(10.5 \pm 2.0)$. Between aOSE and aCSE, however, no significant differences were found $(\mathrm{Z}=-0.414, \mathrm{p}=0.679)$. In addition, there was no significant interaction effect $\left(\mathrm{F}_{1,23}=1.274, \mathrm{p}=0.271, \eta_{\mathrm{p}}{ }^{2}\right.$ $=0.052)$ or group effect $\left(\mathrm{F}_{1,23}=0.003, \mathrm{p}=0.956, \eta_{\mathrm{p}}{ }^{2}\right.$ $=0.000$ ) in blood lactate concentration. The time effect was significant $\left(\mathrm{F}_{1,23}=45.695, \mathrm{p}<0.001, \eta_{\mathrm{p}}{ }^{2}=0.665\right)$, with higher blood lactate concentrations at post-test (see Fig. 3).

\section{Brain-derived neurotrophic factor}

Outcome values of $\mathrm{BDNF}_{\mathrm{P}}$ and $\mathrm{BDNF}_{\mathrm{S}}$ are shown in Table 3. No interaction effect $\left(\mathrm{F}_{2,58}=0.392, \mathrm{p}=0.678\right.$, $\left.\eta_{\mathrm{p}}{ }^{2}=0.013\right)$ or main group effect $\left(\mathrm{F}_{2,58}=1.039\right.$, $\mathrm{p}$ $\left.=0.360, \eta_{\mathrm{p}}{ }^{2}=0.035\right)$ could be observed for $\mathrm{BDNF}_{\mathrm{p}}$. Nevertheless, we found a main time effect $\left(\mathrm{F}_{1,58}\right.$ $\left.=6.730, \mathrm{p}=0.012, \eta_{\mathrm{p}}{ }^{2}=0.104\right)$ with significantly increased $\mathrm{BDNF}_{\mathrm{P}}$ concentrations after the aOSE session $\left(\mathrm{F}_{1,23}=5.135, \mathrm{p}=0.033, \eta_{\mathrm{p}}^{2}=0.183\right)$. No significant time effect, but a tendency, was observed for the aCSE session $\left(\mathrm{F}_{1,23}=3.572, \mathrm{p}=0.074, \eta_{\mathrm{p}}{ }^{2}=0.138\right)$. The absolute changes in $\mathrm{BDNF}_{\mathrm{P}}$ showed no significant differences between groups (see Fig. 4). For $\mathrm{BDNF}_{\mathrm{S}}$, we found a significant interaction effect $\left(\mathrm{F}_{2,58}=11.619\right.$, $\left.\mathrm{p}=<0.001, \eta_{\mathrm{p}}{ }^{2}=0.286\right)$ and main time effect $\left(\mathrm{F}_{1,58}\right.$ $\left.=42.567, \mathrm{p}<0.001, \eta_{\mathrm{p}}{ }^{2}=0.423\right)$, while no main group effect occurred $\left(\mathrm{F}_{2,58}=0.113, \mathrm{p}=0.894, \eta_{\mathrm{p}}{ }^{2}=0.004\right)$.

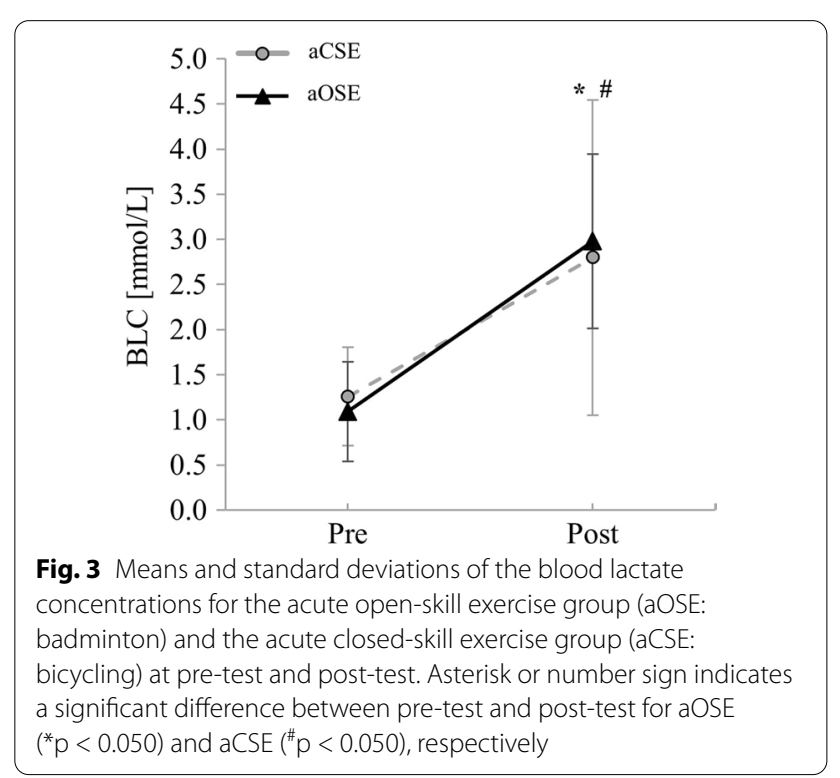


Table 3 Acute effects of OSE and CSE on blood levels of BDNF, BDNF, IGF-1 and IL-6

\begin{tabular}{|c|c|c|c|c|c|c|}
\hline \multirow[t]{3}{*}{ Variable } & \multicolumn{4}{|l|}{ Intervention group } & \multirow{2}{*}{\multicolumn{2}{|c|}{ CG }} \\
\hline & \multicolumn{2}{|l|}{ aOSE } & \multicolumn{2}{|l|}{ aCSE } & & \\
\hline & Pre & Post & Pre & Post & Pre & Post \\
\hline $\mathrm{BDNF}_{\mathrm{p}}(\mathrm{pg} / \mathrm{ml})$ & 1599.54 (738.57) & $1804.63^{*}(780.00)$ & $1376.26(621.73)$ & $1682.04^{\#}(807.15)$ & $1825.43(927.54)$ & $1950.14(1043.07)$ \\
\hline $\mathrm{BDNF}_{\mathrm{S}}(\mathrm{pg} / \mathrm{ml})$ & $27,525.00(6781.45)$ & $29,783.33^{* *}(7433.40)$ & 26,473.91 (6317.31) & $29,556.52^{* *}(6929.83)$ & $27,685.71(7380.52)$ & $27,528.57(6848.74)$ \\
\hline IGF-1 (ng/ml) & $183.33(66.83)$ & $192.13^{* *}(65.65)$ & $192.42(70.50)$ & $201.29^{* *}(75.30)$ & $174.50(63.66)$ & $174.00(64.94)$ \\
\hline IL-6 (ng/L) & $2.15(1.65)$ & $3.25^{*}(2.90)$ & $1.60(1.18)$ & $2.75^{* *}(2.88)$ & $1.55(0.53)$ & $1.60(0.60)$ \\
\hline
\end{tabular}

Mean values (standard deviation) of $\mathrm{BDNF}_{\mathrm{p}}, \mathrm{BDNF}_{\mathrm{S}}$, and serum IGF-1-as well as median values (interquartile range) of serum IL- 6 at pre-test and post-test For $\mathrm{BDNF}_{\mathrm{p}}, \mathrm{BDNF}_{\mathrm{S}}$, and IGF-1, parametric tests were used. For IL-6, non-parametric tests were used $B D N F$ brain-derived neurotrophic factor; IGF-1 insulin-like growth factor 1; IL-6 interleukine-6 Asterisk indicate significant difference between pre-test and post-test $\left({ }^{*} 0.050>p \geq 00.001 ;{ }^{* *} p<0.001\right)$ Number sign indicate a tendency for difference between pre-test and post-test $\left({ }^{\#} 0.100>p \geq 0.050\right)$

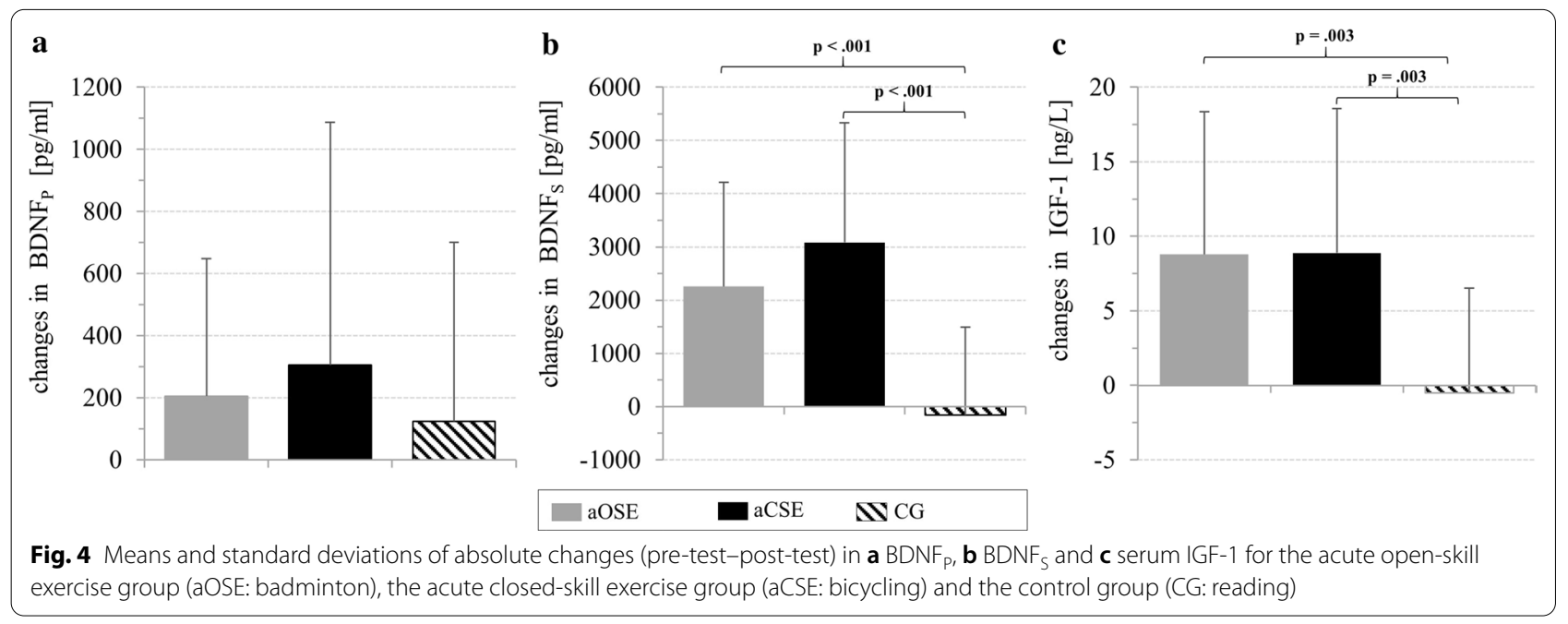

In both, the aOSE and the aCSE group, $\mathrm{BDNF}_{\mathrm{S}}$ increased significantly from pre-test to post-test $\left(\mathrm{F}_{1,23}\right.$ $=32.145, \mathrm{p}<0.001, \eta_{\mathrm{p}}{ }^{2}=0.582$ and $\mathrm{F}_{1,23}=43.374, \mathrm{p}$ $<0.001, \eta_{\mathrm{p}}^{2}=0.663$, respectively). As shown in Fig. 4, the increase in $\mathrm{BDNF}_{\mathrm{S}}$ was significantly higher in the aOSE and the aCSE group compared to the CG.

\section{Insulin-like growth factor 1}

An overview of the IGF-1 values can be found in Table 3. For the IGF-1, a significant interaction effect $\left(\mathrm{F}_{2,59}=5.964, \mathrm{p}=0.005, \eta_{\mathrm{p}}^{2}=0.162\right)$ and main time effect $\left(\mathrm{F}_{1,59}=22.965, \mathrm{p}<0.001, \eta_{\mathrm{p}}{ }^{2}=0.280\right)$ were observed. Follow-up tests revealed that the IGF-1 concentrations were significantly increased after a single OSE or CSE session (aOSE: $\mathrm{F}_{1,23}=20.279, \mathrm{p}<0.001$, $\eta_{\mathrm{p}}{ }^{2}=0.469$ and aCSE: $\mathrm{F}_{1,23}=20.217, \mathrm{p}<0.001, \eta_{\mathrm{p}}{ }^{2}$ $=0.468$, respectively). In addition, the absolute changes in the IGF-1 were significantly higher in the aOSE and the aCSE group compared to the CG (see Fig. 4).

\section{Interleukine-6}

Outcome values regarding IL- 6 are shown in Table 4. Since no differences between groups were found during the pre-test, an initial homogeneity can be assumed. IL-6 values increased significantly from pre-test to post-test (time effect) in the aOSE and the aCSE group $(\mathrm{Z}=-3.460, \mathrm{p}=0.001, \mathrm{r}=0.706$ and $\mathrm{Z}=-4.110$, $\mathrm{p}<0.001, \mathrm{r}=0.839$, respectively). In post-test, participants from the aOSE and the aCSE group showed significantly higher IL-6 levels compared to the participants of the CG $(Z=-3.230, p=0.001, r=0.524$ and $\mathrm{Z}=-3.136, \mathrm{p}=0.002, \mathrm{r}=0.509$, respectively). Statistical analyses of absolute changes in IL- 6 concentration indicates a significant larger increase in the aOSE and 
Table 4 Chronic effects of OSE and CSE on blood levels of BDNF, BDNF, IGF-1 and IL-6

\begin{tabular}{|c|c|c|c|c|c|c|}
\hline \multirow[t]{2}{*}{ Variable } & \multicolumn{3}{|l|}{ cOSE } & \multicolumn{3}{|l|}{ cCSE } \\
\hline & Pre & Post & Change & Pre & Post & Change \\
\hline $\mathrm{BDNF}_{\mathrm{p}}(\mathrm{pg} / \mathrm{ml})$ & $1695.0(837.5)$ & $1810.0(760.0)$ & $+35.0(1392.5)$ & $1620.0(810.0)$ & $1850.0(2168.0)$ & +63.0 (1739.0) \\
\hline $\mathrm{BDNF}_{\mathrm{S}}(\mathrm{pg} / \mathrm{ml})$ & $25,200.0(4800.0)$ & $27,400.0^{*}(7650.0)$ & $+2450.0(4625.0)$ & $30,700.0(6450.0)$ & $32,400.0(14,050.0)$ & $+3600.0(11,500.0)$ \\
\hline IGF-1 (ng/ml) & $209.5(96.8)$ & $158.5^{*}(90.3)$ & $-34.5(34.25)$ & $180.0(81.0)$ & $146.0^{\#}(63.0)$ & $-21.0(86.5)$ \\
\hline IL-6 (ng/L) & $1.6(1.6)$ & $5.4^{*}(2.4)$ & $+3.8(2.8)$ & $1.5(4.7)$ & $5.9(1.4)$ & $+4.0(5.4)$ \\
\hline
\end{tabular}

Median values (interquartile range) of $\mathrm{BDNF}_{\mathrm{p}} \mathrm{BDNF}_{\mathrm{S}}$, serum IGF-1, and serum IL- 6 at pre-test and post-test $B D N F$ brain-derived neurotrophic factor; IGF-1 insulin-like growth factor 1 ; IL- 6 interleukine- 6 Asterisk indicates a significant difference between pre-test and post-test $\left({ }^{*} 0.050>p \geq 0.001\right)$ Number sign indicates a tendency for difference between pre-test and post-test $\left({ }^{\sharp} 0.100>p \geq 0.050\right)$



the aCSE group compared to the CG. In addition, the absolute increase in IL-6 was significantly higher in the aOSE condition compared to the aCSE condition (see Fig. 5).

\section{Chronic effects}

Seven participants were excluded from data analyses due to injuries or low attendance rate (under 75\%). This left a total of 15 participants ( 9 in the CCSE group and 6 in the cOSE group). Due to the small remaining sample size, we plotted the pre- and post-training levels of $\mathrm{BDNF}_{\mathrm{p}}, \mathrm{BDNF}_{\mathrm{S}}$, IGF-1 and IL- 6 in Fig. 6 to better illustrate the results. The average attendance rate of the remaining participants from the oCSE and CCSE group was $84.7 \pm 7.5 \%$ and $91.7 \pm 7.9 \%$, respectively. Except for body height, the participants in both groups exhibited comparable characteristics (see Table 2).

\section{Brain-derived neurotrophic factor}

Regarding $\mathrm{BDNF}_{\mathrm{p}}$ and $\mathrm{BDNF}_{\mathrm{S}}$, we did not find any between group differences at pre-test $(Z=-0.825$, $\mathrm{p}=0.456$ and $\mathrm{Z}=-1.651, \mathrm{p}=0.607)$ or at post-test $(\mathrm{Z}=-0.236, \mathrm{p}=0.864$ and $\mathrm{Z}=-0.885, \mathrm{p}=0.388)$ (see Table 4). In addition, no time effects were observed for $\mathrm{BDNF}_{\mathrm{p}}$ (cOSE: $\mathrm{Z}=-0.105, \mathrm{p}=0.917$; cCSE: $\mathrm{Z}$ $=-1.007, p=0.314)$. For $B D D N F_{S}$, while no time effect for the cCSE group was observed $(\mathrm{Z}=-1.007, \mathrm{p}$ $=0.314$ ), a significant time effect with a large effect size was identified for the cOSE group, with higher $\mathrm{BDNF}_{\mathrm{S}}$ levels at post-test compared to pre-test $(\mathrm{Z}=-1.992$, $\mathrm{p}=0.046, \mathrm{r}=0.813$ ). The graphs in Fig. 6 show that changes in BDNF can be-depending on participantin opposite directions. With the exception of $\mathrm{BDNF}_{\mathrm{P}}$ in the cOSE group, an increase of basal BDNF levels can be seen for most of the participants. Not unexpectedly, the direction of change is for most participants identical for $\mathrm{BDNF}_{\mathrm{S}}$ and $\mathrm{BDNF}_{\mathrm{P}}$.

\section{Insulin-like growth factor 1}

IGF-1 showed no significant between group differences at pre-test $(\mathrm{Z}=-0.943, \mathrm{p}=0.388)$ or at post-test $(\mathrm{Z}=-0.471, \mathrm{p}=0.689$ ) (see Table 4). Regarding the cOSE group, a significant decrease in the IGF-1 levels could be observed $(\mathrm{Z}=-2.201, \mathrm{p}=0.028, \mathrm{r}=0.899$ ). The IGF-1 levels also decreased in the cCSE group. The decrease in the IGF-1 levels from pre-test to post-test failed to reveal a significant time effect $(\mathrm{Z}=-1.718$, $\mathrm{p}=0.086)$. However, the statistical effect size was large $(r=0.573)$. Figure 6 shows that basal IGF-1 levels decreased in all but two participants from the cCSE group, and was reduced in all participants of the CCSE group after 12 weeks of intervention.

\section{Interleukin-6}

No significant pre-test or post-test differences were observed for IL-6 between groups (pre-test: $\mathrm{Z}=0.000$, 


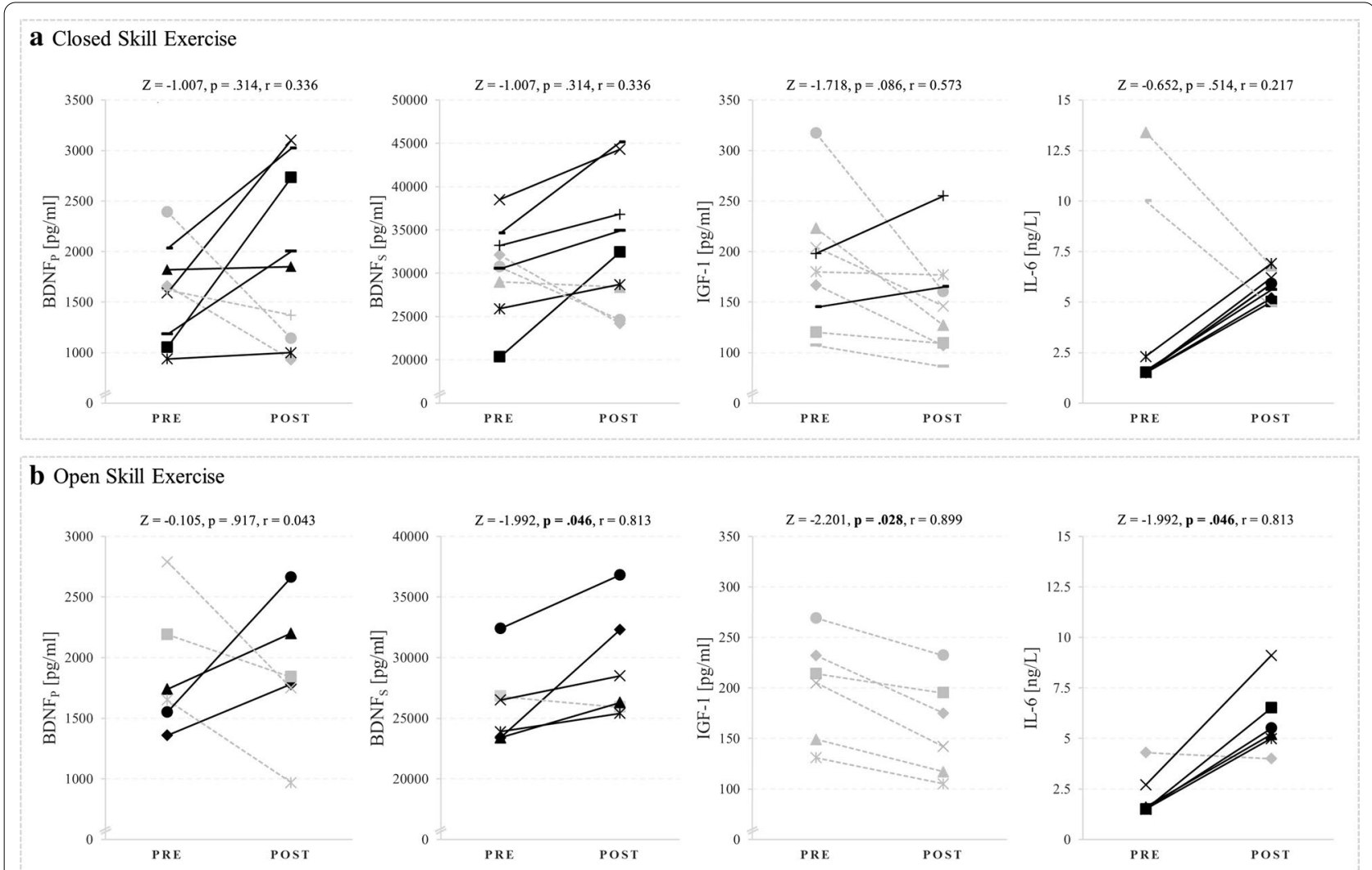

Fig. 6 Absolute values of BDNF ${ }_{p}, B D_{N}$, serum IGF-1 and serum IL-6 from pre-test (T1: before intervention) to post-test (T3: after 12 weeks of intervention) for the $\mathbf{a}$ COSE-group and the $\mathbf{b}$ CCSE-group. The symbols in $\mathbf{a}$ and $\mathbf{b}$ represent one and the same person

$\mathrm{p}=1.000$; post-test: $\mathrm{Z}=-0.730, \mathrm{p}=0.689$ ) (see Table 4). While there was no significant time effect for the cCSE group $(\mathrm{Z}=-0.652$, $\mathrm{p}=0.514)$, a significant time effect was observed for the cOSE group, with higher IL-6 levels at post-test compared to pre-test $(\mathrm{Z}=-1.992, \mathrm{p}=0.046, \mathrm{r}=0.813)$. Figure 6 indicates 2 participants in the cOSE group with substantially elevated IL- 6 levels at pre-test that seemed to be reduced back to normal levels after 12 weeks of intervention. When these two "outliers" with untypical high IL-6 levels are removed from the statistical analysis, the observed trend for the other participants towards an increase in IL-6 becomes statistically significant ( $\mathrm{Z}$ $=-2.371, \mathrm{p}=0.018, \mathrm{r}=0.896$ ). For the cOSE group, a trend towards increased IL- 6 post-test is obvious.

While such an analysis for different neurotrophic and immunomodulatory molecules in the blood of study participants might open up interesting perspectives for the overall evaluation of sport interventions our current sample size is too low to draw clear conclusions.

\section{Discussion}

In this study, we compared the acute and chronic effects of OSE and CSE on plasma and serum levels of BDNF, serum IGF-1, and serum IL-6 in healthy older adults. These neurotrophic factors and cytokines are assumed to modulate specific molecular and cellular pathways promoting neuroplasticity, that can enable cognitive improvements and the maintenance of brain integrity $[20,23,25,44,65-67]$. Based on our results presented above, the main findings of our study were two-fold: first, we could observe that $\mathrm{BDNF}_{\mathrm{p}}, \mathrm{BDNF}_{\mathrm{S}}$, IGF-1, and IL-6 levels were increased in response to both exercise types (aOSE and aCSE) after a single session of $30 \mathrm{~min}$. Differences between the exercise types could only be found for serum IL-6, suggesting that a single badminton session (aOSE) compared with a single bicycle session (aCSE) leads to an elevated IL-6 level in healthy older adults. Second, after 12 weeks of training, the basal levels of $\mathrm{BDNF}_{\mathrm{S}}$ and IL-6 increased whereas the basal level of IGF-1 decreased in the cOSE group, without differences between groups. 


\section{Acute effects}

$\mathrm{BDNF}_{\mathrm{S}}$ was significantly increased after both exercise types, suggesting that a single session of either an OSE (badminton) or a CSE (bicycling) could acutely increase peripheral $\mathrm{BDNF}_{\mathrm{S}}$ levels in healthy older adults. Previous studies investigating the acute effect of a single exercise session also found elevated peripheral $\mathrm{BDNF}_{\mathrm{S}}$ levels in older and younger healthy people [56, 68-73]. Hung et al. [56] compared the effect of a single badminton session with a single running session ( $30 \mathrm{~min}$ at $60 \%$ of HRR) on $\mathrm{BDNF}_{\mathrm{S}}$ production in twenty young (23.15 years) healthy males and could observe similar effects. However, in this study, the authors reported that the badminton session resulted in a significantly higher $\mathrm{BDNF}_{\mathrm{S}}$ level compared to the running session [56]. In our investigation, we could not observe any differences in $\mathrm{BDNF}_{\mathrm{S}}$ levels between exercise types. Although, BDNF is also expressed in vascular endothelial cells [74] and the skeletal muscle cells [75], the most prominent source of BDNF is the brain, where it is expressed at highest levels in the hippocampus and the neocortex [76-78]. Since BDNF can cross the blood-brain barrier [79], Rasmussen et al. [80] estimated that in humans, at rest and during exercise, $70-80 \%$ of circulating BDNF in the blood stream (determined in venous blood) originates from the brain. Strong evidence suggests that the exercise-induced changes in circulating BDNF levels are affected by a host of factors including general exercise variables such as the type (e.g., cycling, playing badminton, dancing), the intensity (describes how strenuous the exercise is), and the duration (time period of a particular exercise or entire exercise session) as well as individual characteristics such as age $[10,23,49,73$, 81-84]. Regarding the exercise variables, both qualitative characteristics (e.g., exercise type and complexity) and quantitative characteristics (e.g., intensity and duration) need to be considered to clarify the exercise dose $[10,85,86]$. According to the distinction between OSE and CSE, the classification is based on qualitative exercise variables such as the predictability of the performing environment (dynamic and less predictable vs. static and mostly predictable environments) and the exercise complexity (coordinative and/or cognitive demands) [50, 87]. To take into account the differences between OSE and CSE in terms of their beneficial effects on cognitive functions and the underlying molecular and cellular mechanisms, all relevant quantitative exercise characteristics must be set equally. In the study of Hung et al. [56] as well as in our study, exercise duration (30 min) and intensity (average heart rate was used as a proxy for the internal load) were matched between OSE and CSE. However, while moderate continuous running and/or bicycling (CSE) are predominantly repetitive (cyclic) and internally-paced movements, badminton (OSE) is more externally-paced and consists of dynamic movements that, among other things, manifest themselves through rapid changes in movement direction and speed [88-90]. Therefore, it could be assumed that the internal load (as a proxy of exercise intensity) remains relatively constant during running or bicycling, while it fluctuates during a badminton session. Regarding the findings of Hung et al. [56], peaks in internal load during the badminton session could be one reason why $\mathrm{BDNF}_{\mathrm{S}}$ levels were significantly higher compared to running. Compared to Hung et al. [56], our participants were much older and probably less agile. Thus, in our older cohort there were less pronounced fluctuations in internal load during the badminton session which could be one possible reason, among other factors, why we did not observe statistically significant differences in $\mathrm{BDNF}_{\mathrm{S}}$ levels between the aOSE and the aCSE group. However, this remains speculative.

It should be noted that we did not screen our participants for symptoms of depression and therefore we cannot rule out an influence on our results due to underlying depressive disorders. Previous studies have shown decreased basal levels of $\mathrm{BDNF}_{\mathrm{S}}$ in elderly people with depression compared to people without depression [91, 92]. Indeed, decreased $\mathrm{BDNF}_{S}$ levels may contribute to atrophy of certain limbic structures, including the hippocampus and prefrontal cortex, which have been observed in depressed adults [93, 94]. However, the mean values and standard deviations of the basal $\mathrm{BDNF}_{\mathrm{S}}$ and $\mathrm{BDNF}_{\mathrm{p}}$ levels presented in our study are comparable to the results of existing studies with healthy elderly adults $[45,95,96]$.

While levels of $\mathrm{BDNF}_{\mathrm{S}}$ reflect $\mathrm{BDNF}$ that is stored in platelets, $\mathrm{BDNF}_{\mathrm{P}}$ concentrations reads out the freely circulating BDNF in the absence of platelet activation [34]. We observed that $\mathrm{BDNF}_{\mathrm{p}}$ levels increased after both acute exercise session (aOSE: significant time effect; aCSE: tendentious time effect). However, in contrast to $\mathrm{BDNF}_{S}$, there were no differences, neither between the active groups (aOSE vs. aCSE) nor between any active group and the inactive CG (aOSE vs. CG and aCSE vs. CG). Recent studies have shown that $\mathrm{BDNF}_{\mathrm{P}}$ levels did not significantly increase after a single session of aerobic [97-99] or resistance exercises [100] in young and older participants. Nofuij et al. [98] observed a nonsignificant increase in $\mathrm{BDNF}_{\mathrm{P}}$ immediately after, $30 \mathrm{~min}$ after, and 60 min after low $\left(40 \% \mathrm{VO}_{2 \max }\right)$, moderate $(60 \%$ $\left.\mathrm{VO}_{2 \max }\right)$, and high $\left(100 \% \mathrm{VO}_{2 \max }\right)$ intensity exercise tests (performed on a bicycle), while $\mathrm{BDNF}_{\mathrm{S}}$ was significantly increased immediately after the low intensity exercise test. However, Cho et al. [101] have shown that both, $\mathrm{BDNF}_{\mathrm{S}}$ and $\mathrm{BDNF}_{\mathrm{P}}$ are significantly increased immediately after a maximal treadmill test in 18 healthy male students. Furthermore, Rasmussen et al. [80] reported 
that $\mathrm{BDNF}_{\mathrm{p}}$ is increased after 4 hours of ergometer rowing corresponding to an intensity $10-15 \%$ below the lactate threshold but not after 2 hours. It is conceivable that an high intra- and inter-individual variability, caused by the dynamics of BDNF uptake and release, or other variables, like training status or neurological status, might be among the factors that account for the above mentioned inconsistent study results regarding the plasma BDNF levels [99]. We can only speculate, that acute changes in $\mathrm{BDNF}_{\mathrm{p}}$ between the active groups and the inactive control group could become statistically significant with a higher sample size or another exercise prescription (e.g., prolonged exercise duration).

With regard to IGF-1, we observed that a single badminton session (aOSE) as well as a single session of bicycling (aCSE) leads to an increased IGF-1 concentration in blood serum. Existing studies indicate that the exercise-related release of IGF-1 is highly variable and is a function of exercise intensity, duration and modality. While IGF-1 serum levels were increased after short bouts (10-22 min) of high- $[28,70,102]$ and low-intensity [28] cycling, other studies have reported a nonsignificant increase in serum IGF-1 following a single session of moderate swimming [103] and high intensity bicycling [69]. However, there is also evidence that the acute exercise-related release of IGF-1 is transient, peaking after 5-10 min of exercise and return to baseline or to significantly lower levels within 30-60 min after exercising [28, 104, 105]. Berg and Bang [104] suggested that the rapid increase in serum IGF-1 concentration following acute exercise is due to the release of IGF-1 from tissue stores (i.e., in the skeletal muscle) rather than to the peptide synthesis in the liver or muscle cells [67]. While findings of previous studies indicate that increased basal IGF-1 levels after long-term ( 24 up to 52 weeks) resistance training improve behavioural (several cognitive functions) and physiological (P3-amplitude) indicators for brain function [106, 107], an acute increase in IGF-1 following a single exercise session does not correlate with functional improvements [105]. These results suggest that the beneficial effect of IGF-1 relies on longterm mechanisms such as angiogenesis, and potentially, the regulation of synaptic plasticity in the brain $[44,67$, 108-110].

Regarding IL-6, our results show an acute exerciserelated increase in IL-6 in both active groups, with significantly higher changes in the aOSE group. Strong evidence suggests that IL- 6 is expressed by myocytes in contracting muscle fibres e.g., due to physical exercising [111-113]. Interestingly, IL-6 is also expressed by the brain during prolonged physical exercise $[47,114]$, for instance, as a signal of metabolic stress within the brain or as a consequence of increased brain activity [33,
115]. Chronically elevated levels of IL-6 are often associated with adverse health effects (e.g., cognitive declines, metabolic disorders). Importantly, results from human and animal studies showed that IL-6 stimulates the production of anti-inflammatory cytokines (e.g., IL-10) [33, 48], supresses expression of tumor necrosis factor- $\alpha$ [48], regulates neuronal functions [24], stimulates neurogenesis (i.e., the process of creating new neurons and glial cells from stem cells) [24] and acts neuroprotective [116]. Therefore, the acute exercise-induced release of IL-6 could be involved in mediating some positive effects for brain health and cognitive functions. It is well known that the exercise type, intensity, duration as well as the mass of recruited skeletal muscles determines the magnitude of the acute exercise-induced release of IL- 6 [48, 115, 117]. Since bicycling involves a limited skeletal muscle mass (lower extremities) and badminton involves nearly all muscle groups of the whole body, it is not surprising that the aOSE group leads to a significantly higher release of IL- 6 into the blood compared to the aCSE group. Hence, we speculate that the group differences for acute changes of IL-6 (aOSE: badminton vs. aCSE: cycling) could be explained by the magnitude of involved musculature rather than by the inherent differences between OSE and CSE (i.e., predictability of the performing environment and the exercise complexity).

\section{Chronic effects}

After 12 weeks of training, basal $\mathrm{BDNF}_{\mathrm{S}}$ levels were increased in both groups (cOSE: $+2450.0 \mathrm{pg} / \mathrm{ml}$; cCSE: $+3600.0 \mathrm{pg} / \mathrm{ml})$. Although the absolute changes in the cCSE group are greater than in the COSE group, only the peripheral $\mathrm{BDNF}_{\mathrm{S}}$ levels of the cOSE group changed significantly from pre-test to post-test. The majority of previous studies investigating the chronic effects of regular physical-exercise (i.e. training) on basal levels of peripheral BDNF concentrations focused on aerobic and strength training with inhomogeneous results $[49,51,81$, $82,118,119]$. So far, existing studies report unchanged $[45,120,121]$, increased $[83,122,123]$ and reduced [71, $124,125]$ basal $\mathrm{BDNF}_{\mathrm{S}}$ and $\mathrm{BDNF}_{\mathrm{P}}$ levels in older individuals following an aerobic and/or resistance training. Additionally, a current meta-analysis by Marinus et al. [49] indicates that a combined aerobic-strength training is more effective in increasing peripheral BDNF concentrations in the elderly population than an isolated aerobic training. However, there is no consensus about the most beneficial exercise variables (intensity, duration, type of training) and training variables (frequency, density, period) [10] to induce an increase in peripheral BDNF concentrations. Regarding the exercise type, Grégoire et al. [126] observed that after 8 weeks of participation, a one-hour training intervention performed three times 
a week and including gross motor activities (juggling and ball-throwing exercises towards a target) induced a greater increase in basal $\mathrm{BDNF}_{\mathrm{P}}$ levels than interventions including aerobic and strength training units in older healthy people. In addition, Rehfeld et al. [127] noticed in their training intervention study ( 6 month, $2 \times$ per week, $90 \mathrm{~min}$ ) that dancing increased basal $\mathrm{BDNF}_{\mathrm{p}}$ levels in older healthy adults more than a health-related exercise training (including aerobic, strength and flexibility training units). In the same study the increase in grey and white matter volume in multiple brain areas was more pronounced in the dancing group (see also: $[95,128]$ ). These results support the hypothesis, that physical exercises with sensory enrichment and coordinative-cognitive demands (e.g., OSE like dancing or badminton) have more pronounced effects, compared to physical exercises with no or low sensory and coordinative demands, respectively (e.g., CSE like an combined strengthendurance training), on neurophysiological mechanisms (e.g., the release of neurotrophic factors such as BDNF) and structural brain changes $[95,129]$. In our study, we observed unchanged $\mathrm{BDNF}_{\mathrm{P}}$ levels and increased $\mathrm{BDNF}_{\mathrm{S}}$ levels (only statistically relevant for the cOSE group). However, we could not find any differences between the groups, neither for absolute values at post-test nor for the absolute changes from pre-test to post-test. This lack off an effect might result from two factors: (i) the low number of study participants and/or (ii) an insufficient "dose" of the physical exercise/training regime which depends on exercise prescription (e.g., exercise duration, training frequency, and training density) [10].

Although physical training, especially strength training, is traditionally associated with increased concentration of growth factors such as IGF-1 in the blood stream, we could not observe an increase in basal IGF-1 concentrations in blood serum for both groups. To the contrary, we observed in both groups a decrease of basal IGF-1 levels at the end of the 12-week intervention (with statistically significant changes in the cOSE group and a tendency towards significance in the CCSE group). This finding is in accordance with the observation of comparable studies which reported a decrease of basal IGF-1 levels after endurance training and strength training for young individuals [130] and older individuals [131]. In this regard, it should be noted that the rate of synthesis of IGF-1 does also depend on non-exercise related factors, such as the nutritional status [104], age [132] and availability of human growth hormone (GH) [133]. In general, a positive neurocognitive effect of IGF-1 has been observed in several intervention studies, in which a training-induced (aerobic and strength training) increase in basal IGF-1 concentration was associated with improved cognitive functions in older individuals $[106,134,135]$. In particular, in older individuals, several studies reported that an increase in basal levels of IGF-1 in response to a long-term aerobic training intervention is associated with improved functional connectivity, cognitive functions, and increased hippocampal volume, although the basal concentration of this growth factor was not affected by the training intervention $[45,131]$. One might speculate that repeated rapid short-term changes in neuropeptides such as IGF-1 during and following physical exercises can trigger neurobiological processes that can converge into various neurocognitive changes (e.g., angiogenesis, structural and functional brain changes) if those short-term changes occur over a distinct time period repetitively. Since the exact mechanisms that explain the relationship between the exercise-induced alterations of IGF-1 and neurocognitive processes are sparsely understood [25, 32], this is an unresolved issue. With regard to the comparison between the COSE and cCSE group, our study results do not show any advantages of either training or exercise type.

With regard to IL-6, our results indicate that the basal IL-6 concentration in blood serum increased in both groups (cOSE: $+3.8 \mathrm{ng} / \mathrm{l}$; cCSE: $+4.0 \mathrm{ng} / \mathrm{l}$ ), whereas only changes from the cOSE group became statistically significant. The possible lack of significant changes in IL-6 for the cCSE group might be due to the relatively small sample size and relatively high inter-individual differences at pre-test (see interquartile range and Fig. 6). Contrary to our results, Forti et al. [121] showed that basal IL- 6 levels significantly decreased after 12 weeks of strength training (70-80\% 1-RM, $3 \times$ per week) in 20 older adults. However, the reported absolute changes were relatively small, with a median value of approximately $0.45 \mathrm{ng} / \mathrm{l}$ (absolute changes) and the authors could not observe significant differences in changes of IL-6 in comparison to an inactive control group. Other studies, performing a strength training with elderly participants, did not detect statistically significant changes in basal IL-6 levels after six $(3 \times 10$ repetitions of $50 \%$ up to $70-80 \% 1-R M, 2 \times$ per week [136]) and ten $(3 \times 8$ repetitions of $70-80 \%$ $1-\mathrm{RM}, 2 \times$ per week [137]) weeks of training. While prolonged and exacerbated IL- 6 exposure is associated with inflammatory processes and numerous chronical disease such as dementia [138], it is not clear whether IL-6 is the cause or only a marker of disease $[47,139]$. During physical exercise, peripheral IL-6 concentration was reported to increase acutely and returning to baseline level within $24 \mathrm{~h}[117,140]$. In this context, IL-6 is rather assumed to have an anti-inflammatory effect and could be a factor by which regular exercise might reduce chronic (low-grade) inflammation and the risk for neurological disorders $[115,116,141]$. Since IL-6 
plays multiple roles in a wide array of biological processes in the human organism [33, 48, 142, 143], further research is needed to gain a better understanding of the relationship between exercise/training, the acute/ chronic alterations of IL- 6 and its effect on neurocognitive processes.

However, the present study is not without limitations that we have to acknowledge. First, we admit that there could be a possible bias due to the fact that badminton (aOSE) involves whole-body movements with weightbearing whereas bicycling (aCSE) involves mainly lowerbody movements without weight-bearing. Therefore, it might be possible that the muscle mass, which is involved in the body movement, may affect the acute exercisereleased response of physiological markers (e.g., BDNF, IGF-1, IL-6). On the one hand, we chose badminton as OSE because it represents an economic and popular sports game, which involves physical as well as cognitive demands $[90,144]$. On the other hand, due to our older participants, we chose bicycling instead of treadmill running to reduce the risk of falls and injuries. Secondly, although we have checked the average heart rate, subjective perception of effort, and blood lactate concentration during or immediately after each exercise, to ensure equal intensities between the aOSE and the aCSE group, we cannot be sure that during the exercise session, the internal load was exactly the same. This limitation should be taken into account when designing future studies. Third, the exercise sessions from the first investigation (acute effects; aOSE: badminton and aCSE: bicycling) and the second investigation (chronic effects; cOSE: performing different sport-games and CCSE: combined strengthendurance training) are not completely comparable without limitations. During the acute exercise sessions, intensity of exercise was set to $60 \pm 5 \%$ of participants individual HRR and the heart rate was continuously controlled using a heart rate monitor. In the second investigation, the training intensity was individually adjusted to the subjective perceived exertion of the participants using the CR-10 Scale. Training intensity was individually adjusted so that each participant rated the intensity as a 7 out of 10 . We have chosen to use the CR-10 scale for the chronic intervention because of methodological reasons. According to the American College of Sports Medicine position stand [145] and Noble et al. [62], both descriptions of intensity $(60 \pm 5 \%$ of HRR and a score of 7 on the CR-10 scale) are defined as vigorous exercise intensity (i.e., hard to very hard). However, the first and second investigation (i.e., acute vs. chronical) differ in the type of exercise/training (e.g., endurance exercise vs. combined strength-endurance exercise/training). Therefore, conclusions with regard to acute to chronic effects or vice versa should be interpreted cautiously. Finally, a high number of dropouts during the intervention study left a relatively small number of participants which could be analyzed.

\section{Conclusion}

In conclusion, the present study examined possible differences between acute and chronic effects of OSE and CSE on BDNF $_{S}$, BDNF $_{\mathrm{P}}$ as well as IGF-1 and IL-6 serum levels. We observed that both exercise types were equally efficient to acutely increase the $\mathrm{BDNF}_{\mathrm{S}}, \mathrm{BDNF}_{\mathrm{P}}$, IGF-1 and IL- 6 serum levles in healthy older adults. Compared with cCSE, cOSE led to a significant increase in basal $\mathrm{BDNF}_{\mathrm{S}}$. Although our results tend to support the notion that OSE training is superior in improving some aspects of structural and/or functional brain integrity compared to CSE, it is important to interpret the results with caution due to the relatively small number of participants in the chronical intervention and individual responses, especially regarding the BDNF levels. To prove whether OSE is more effective to enhance or maintain brain health than CSE, further studies are needed that, (i) control for qualitative and quantitative exercise and/or training variables, (ii) measure acute and/or chronic changes of neurotrophic factors with cellular resulution, (iii) determine structural and functional parameters (e.g., hemodynamic response, brain morphology), (iv) analyze behavioural, socioemotional (e.g., sleep, mood), and cognitive functions (e.g., executive functions, memory [20]). Moreover, evaluating of further cohorts (e.g., people with mild cognitive impairments, experts in badminton) is needed to obtain a more general picture regarding possible benefits of OSE over CSE.

\section{Abbreviations}

ANOVA: Analysis of variance; BDNF: Brain-derived neurotrophic factor; BDNFs: Serum Brain-derived neurotrophic factor; $B \mathrm{NNF}_{\mathrm{p}}$ : Plasma Brain-derived neurotrophic factor; CR-10: Category Ratio-10 Scale; CSE: Closed-skill exercise; $H_{\text {max }}$ : Maximum heart rate; HRR: Heart rate reserve; $H_{\text {rest }}$ : Resting heart rate; IGF-1: Insulin-like growth factor 1; IL-6: Interleukin-6; MMSE: Mini-mental State Examination; OSE: Open-skill exercise; RPE: Rating of perceived exertion; $\eta_{p}{ }^{2}$ : Partial eta-squared.

\section{Acknowledgements}

We would like to thank: (1) André Napiontek (Center of Health, Physical Activity and Sports) for supporting the performance of the training-sessions, (2) Margit Schmidt (Institute of Physiology, OVGU) for excellent technical assistance, and (3) all volunteers for their enthusiastic participation in the present study.

\section{Authors' contributions}

TB and LS contributed conception and design of the study; TB, LK, PB and MR organized the database; TB analyzed the data; TB, FK, LK, PB and MR were responsible for performing the research (LK, PB and MR: execution of the training, TB, FK: handling the blood probes); TBR and VL contributed to the blood analysis; TB and FK wrote the first draft of the manuscript; VL, TBR and LS contributed to the review and editing of the manuscript. All authors read and approved the final manuscript. 


\section{Funding}

Open Access funding enabled and organized by Projekt DEAL.

\section{Availability of data and materials}

The datasets generated and/or analyzed during the current are kept in the Department of Sport Science, Otto von Guericke University Magdeburg and are available from the corresponding author on reasonable request.

\section{Declarations}

\section{Ethics approval and consent to participate}

This study was approved by the local ethics-committee of the Medical Faculty at the Otto von Guericke University Magdeburg (29/19). All participants gave written informed consent to participate in the experiments according to the principles stated in the Declaration of Helsinki.

\section{Consent of publication}

Not applicable.

\section{Competing interests}

The authors declare that they have no competing interests.

\section{Author details}

${ }^{1}$ Chair for Health and Physical Activity, Department of Sport Science, Faculty of Humanities, Otto-von-Guericke University Magdeburg, Magdeburg, Germany. ${ }^{2}$ Department of Internal Medicine, Division of Cardiology and Angiology, University Hospital Magdeburg, Magdeburg, Germany. ${ }^{3}$ Department of Informatics and Microsystem Technology, University of Applied Sciences, Kaiserslautern, Germany. ${ }^{4}$ Institute of Physiology, Medical Faculty, Otto-vonGuericke University Magdeburg, Magdeburg, Germany. ${ }^{5}$ Center for Behavioral Brain Sciences, Magdeburg, Germany.

Received: 1 October 2020 Accepted: 8 November 2021

Published: 25 November 2021

\section{References}

1. Peters R. Ageing and the brain. Postgrad Med J. 2006;82:84-8. https:// doi.org/10.1136/pgmj.2005.036665.

2. Harada CN, Natelson Love MC, Triebel KL. Normal cognitive aging. Clin Geriatr Med. 2013;29:737-52. https://doi.org/10.1016/j.cger.2013. 07.002 .

3. Grajauskas LA, Siu W, Medvedev G, Guo H, D'Arcy RCN, Song X. MRI-based evaluation of structural degeneration in the ageing brain: pathophysiology and assessment. Ageing Res Rev. 2019;49:67-82. https://doi.org/10.1016/j.arr.2018.11.004.

4. Raz N, Lindenberger U, Rodrigue KM, Kennedy KM, Head D, Williamson A, et al. Regional brain changes in aging healthy adults: general trends, individual differences and modifiers. Cereb Cortex 2005:15:1676-89. https://doi.org/10.1093/cercor/bhi044.

5. Solé-Padullés C, Bartrés-Faz D, Junqué C, Vendrell P, Rami L, Clemente $I C$, et al. Brain structure and function related to cognitive reserve variables in normal aging, mild cognitive impairment and Alzheimer's disease. Neurobiol Aging. 2009;30:1114-24. https://doi.org/10.1016/j. neurobiolaging.2007.10.008.

6. Andrews KA, Modat M, Macdonald KE, Yeatman T, Cardoso MJ, Leung KK, et al. Atrophy rates in asymptomatic amyloidosis: implications for Alzheimer prevention trials. PLoS ONE. 2013. https://doi.org/10.1371/ journal.pone.0058816.

7. Fiest KM, Jetté N, Roberts JI, Maxwell CJ, Smith EE, Black SE, et al. The prevalence and incidence of dementia: a systematic review and meta-analysis. Can J Neurol Sci. 2016;43(Suppl 1):3-50. https://doi. org/10.1017/cjn.2016.18.

8. Budde H, Schwarz R, Velasques B, Ribeiro P, Holzweg M, Machado S, et al. The need for differentiating between exercise, physical activity, and training. Autoimmun Rev. 2016. https://doi.org/10.1016/j.autrev. 2015.09.004.
9. Caspersen CJ, Powell KE, Christenson GM. Physical activity, exercise, and physical fitness: definitions and distinctions for health-related research. Public Health Rep. 1985;100:126-31.

10. Herold F, Müller P, Gronwald T, Müller NG. Dose-response matters!—a perspective on the exercise prescription in exercise-cognition research. Front Psychol. 2019;10:1-17. https://doi.org/10.3389/fpsyg.2019.02338.

11. Herold F, Törpel A, Schega $L$, Müller NG. Functional and/or structural brain changes in response to resistance exercises and resistance training lead to cognitive improvements - a systematic review. Eur Rev Aging Phys Act. 2019. https://doi.org/10.1186/s11556-019-0217-2.

12. Best JR, Chiu BK, Liang Hsu C, Nagamatsu LS, Liu-Ambrose T. Long-term effects of resistance exercise training on cognition and brain volume in older women: results from a randomized controlled trial. J Int Neuropsychol Soc. 2015;21:745-56. https://doi.org/10.1017/S135561771 5000673.

13. Cheng S-T. Cognitive reserve and the prevention of dementia: the role of physical and cognitive activities. Curr Psychiatry Rep. 2016. https:// doi.org/10.1007/s11920-016-0721-2.

14. Özkaya GY, Aydin H, Toraman FN, Kizilay F, Ozdemir O, Cetinkaya V. Effect of strength and endurance training on cognition in older people. J Sport Sci Med. 2005;4:300-13.

15. Chang YK, Labban JD, Gapin Jl, Etnier JL. The effects of acute exercise on cognitive performance: a meta-analysis. Brain Res. 2012;1453:87101. https://doi.org/10.1016/j.brainres.2012.02.068.

16. Levin $\mathrm{O}, \mathrm{Netz} Y$, Ziv G. The beneficial effects of different types of exercise interventions on motor and cognitive functions in older age: a systematic review. Eur Rev Aging Phys Act. 2017;14:20. https://doi.org/10.1186/ s11556-017-0189-z.

17. Mandolesi L, Polverino A, Montuori S, Foti F, Ferraioli G, Sorrentino P, Sorrentino $G$. Effects of physical exercise on cognitive functioning and wellbeing: biological and psychological benefits. Front Psychol. 2018;9:509. https://doi.org/10.3389/fpsyg.2018.00509.

18. Northey JM, Cherbuin N, Pumpa KL, Smee DJ, Rattray B. Exercise interventions for cognitive function in adults older than 50: a systematic review with meta-analysis. Br J Sport Med. 2018;52:154-60. https://doi. org/10.1136/bjsports-2016-096587.

19. Firth J, Stubbs B, Vancampfort D, Schuch F, Lagopoulos J, Rosenbaum S, Ward PB. Effect of aerobic exercise on hippocampal volume in humans: a systematic review and meta-analysis. Neuroimage. 2018;166:230-8. https://doi.org/10.1016/j.neuroimage.2017.11.007.

20. Stillman CM, Cohen J, Lehman ME, Erickson KI. Mediators of physical activity on neurocognitive function: a review at multiple levels of analysis. Front Hum Neurosci. 2016. https://doi.org/10.3389/fnhum. 2016.00626.

21. Herold F, Hamacher D, Schega L, Müller NG. Thinking while moving or moving while thinking - concepts of motor-cognitive training for cognitive performance enhancement. Front Aging Neurosci. 2018;10:228. https://doi.org/10.3389/fnagi.2018.00228.

22. Törpel A, Herold F, Hamacher D, Müller NG, Schega L. Strengthening the brain-is resistance training with blood flow restriction an effective strategy for cognitive improvement? J Clin Med. 2018. https://doi.org/ 10.3390/jcm7100337.

23. Piepmeier AT, Etnier JL. Brain-derived neurotrophic factor (BDNF) as a potential mechanism of the effects of acute exercise on cognitive performance. J Sport Health Sci. 2015;4:14-23. https://doi.org/10.1016/j. jshs.2014.11.001.

24. Erta M, Quintana A, Hidalgo J. Interleukin-6, a major cytokine in the central nervous system. Int J Biol Sci. 2012;8:1254-66. https://doi.org/ 10.7150/ijbs.4679.

25. Stein AM, Silva TMV, de Coelho FGM, Arantes FJ, Costa JLR, Teodoro E, Santos-Galduróz RF. Physical exercise, IGF-1 and cognition A systematic review of experimental studies in the elderly. Dement Neuropsychol. 2018;12:114-22. https://doi.org/10.1590/1980-57642018dn12-020003.

26. Gold SM, Schulz K-H, Hartmann S, Mladek M, Lang UE, Hellweg R, et al. Basal serum levels and reactivity of nerve growth factor and brainderived neurotrophic factor to standardized acute exercise in multiple sclerosis and controls. J Neuroimmunol. 2003;138:99-105. https://doi. org/10.1016/S0165-5728(03)00121-8.

27. Törpel A, Brennicke M, Kuck M, Behrendt T, Schega L. Effect of blood flow restriction training in combination with a high-intensity interval 
training on physical performance. Int J Sport Exerc Med. 2018. https:// doi.org/10.23937/2469-5718/1510111.

28. Schwarz AJ, Brasel JA, Hintz RL, Mohan S, Cooper DM. Acute effect of brief low- and high-intensity exercise on circulating insulin-like growth factor (IGF) I, II, and IGF-binding protein-3 and its proteolysis in young healthy men. J Clin Endocrinol Metab. 1996;81:3492-7.

29. Cornish SM, Chase JE, Bugera EM, Giesbrecht GG. Systemic IL-6 and myoglobin response to three different resistance exercise intensities in older men. J Aging Phys Act. 2018;26:451-6. https://doi.org/10.1123/ japa.2017-0167.

30. Basso JC, Suzuki WA. The effects of acute exercise on mood, cognition, neurophysiology, and neurochemical pathways: a review. Brain Plast. 2017;2:127-52. https://doi.org/10.3233/BPL-160040.

31. Stimpson NJ, Davison G, Javadi A-H. Joggin'the noggin: towards a physiological understanding of exercise-induced cognitive benefits. Neurosci Biobehav Rev. 2018;88:177-86. https://doi.org/10.1016/j.neubi orev.2018.03.018.

32. Kim S, Choi J-Y, Moon S, Park D-H, Kwak H-B, Kang J-H. Roles of myokines in exercise-induced improvement of neuropsychiatric function. Pflugers Arch. 2019;471:491-505. https://doi.org/10.1007/ s00424-019-02253-8.

33. Norman JE, Rutkowsky J, Bodine S, Rutledge JC. The potential mechanisms of exercise-induced cognitive protection: a literature review. Curr Pharm Des. 2018;24:1827-31. https://doi.org/10.2174/1381612824 666180406105149.

34. Brigadski T, Leßmann V. BDNF: a regulator of learning and memory processes with clinical potential. e Neuroforum. 2014;5:1-11. https:// doi.org/10.1007/s13295-014-0053-9.

35. Numakawa T, Odaka H, Adachi N. Actions of brain-derived neurotrophic factor and glucocorticoid stress in neurogenesis. Int J Mol Sci. 2017;18:2312. https://doi.org/10.3390/ijms18112312.

36. Zhao H, Alam A, San C-Y, Eguchi S, Chen Q, Lian Q, Ma D. Molecular mechanisms of brain-derived neurotrophic factor in neuro-protection: recent developments. Brain Res. 2017;1665:1-21. https://doi.org/10. 1016/j.brainres.2017.03.029.

37. Yamada K, Nabeshima T. Brain-derived neurotrophic factor/TrkB signaling in memory processes. J Pharmacol Sci. 2003;91:267-70. https://doi. org/10.1254/jphs.91.267.

38. Edelmann E, Lessmann V, Brigadski T. Pre- and postsynaptic twists in BDNF secretion and action in synaptic plasticity. Neuropharmacology. 2014;76(Pt C):610-27. https://doi.org/10.1016/j.neuropharm.2013.05. 043.

39. Leal G, Afonso PM, Salazar IL, Duarte CB. Regulation of hippocampal synaptic plasticity by BDNF. Brain Res. 2015;1621:82-101. https://doi. org/10.1016/j.brainres.2014.10.019.

40. Cotman CW, Berchtold NC. Exercise: a behavioral intervention to enhance brain health and plasticity. Trends Neurosci. 2002;25:295-301.

41. Vivar C, Potter MC, van Praag H. All about running: synaptic plasticity, growth factors and adult hippocampal neurogenesis. Curr Top Behav Neurosci. 2013;15:189-210. https://doi.org/10.1007/7854_2012_220.

42. Erickson Kl, Miller DL, Roecklein KA. The aging hippocampus: interactions between exercise, depression, and BDNF. Neuroscientist. 2012:18:82-97. https://doi.org/10.1177/1073858410397054.

43. Brooker GJF, Kalloniatis M, Russo VC, Murphy M, Werther GA, Bartlett PF. Endogenous IGF-1 regulates the neuronal differentiation of adult stem cells. J Neurosci Res. 2000;59:332-41. https://doi.org/10.1002/(SICl) 1097-4547(20000201)59:3\%3c332::AID-JNR6\%3e3.0.CO;2-2.

44. Dyer AH, Vahdatpour C, Sanfeliu A, Tropea D. The role of insulin-like growth factor 1 (IGF-1) in brain development, maturation and neuroplasticity. Neuroscience. 2016;325:89-99. https://doi.org/10.1016/j. neuroscience.2016.03.056

45. Maass A, Düzel S, Brigadski T, Goerke M, Becke A, Sobieray U, et al. Relationships of peripheral IGF-1, VEGF and BDNF levels to exercise-related changes in memory, hippocampal perfusion and volumes in older adults. Neuroimage. 2016;131:142-54. https://doi.org/10.1016/j.neuro image.2015.10.084

46. Nieto-Estévez V, Defterali Ç, Vicario-Abejón C. IGF-l: a key growth factor that regulates neurogenesis and synaptogenesis from embryonic to adult stages of the brain. Front Neurosci. 2016;10:52. https://doi.org/10. 3389/fnins.2016.00052.
47. Gruol DL. IL-6 regulation of synaptic function in the CNS. Neuropharmacology. 2015;96:42-54. https://doi.org/10.1016/j.neuropharm.2014.10. 023.

48. Pedersen BK, Fischer CP. Beneficial health effects of exercise-the role of IL-6 as a myokine. Trends Pharmacol Sci. 2007;28:152-6. https://doi.org/ 10.1016/j.tips.2007.02.002.

49. Marinus N, Hansen D, Feys P, Meesen R, Timmermans A, Spildooren J. The impact of different types of exercise training on peripheral blood brain-derived neurotrophic factor concentrations in older adults: a meta-analysis. Sport Med. 2019;49:1529-46. https://doi.org/10.1007/ s40279-019-01148-z.

50. Gu Q, Zou L, Loprinzi PD, Quan M, Huang T. Effects of open versus closed skill exercise on cognitive function: a systematic review. Front Psychol. 2019;10:1707. https://doi.org/10.3389/fpsyg.2019.01707.

51. Dinoff A, Herrmann N, Swardfager W, Liu CS, Sherman C, Chan S, Lanctôt KL. The effect of exercise training on resting concentrations of peripheral brain-derived neurotrophic factor (BDNF): a meta-analysis. PLoS ONE. 2016. https://doi.org/10.1371/journal.pone.0163037.

52. Herold F, Törpel A, Hamacher D, Budde H, Gronwald T. A discussion on different approaches for prescribing physical interventions-four roads lead to Rome, but which one should we choose? J Pers Med. 2020. https://doi.org/10.3390/jpm10030055.

53. Di Russo F, Bultrini A, Brunelli S, Delussu AS, Polidori L, Taddei F, et al. Benefits of sports participation for executive function in disabled athletes. J Neurotrauma. 2010;27:2309-19. https://doi.org/10.1089/neu. 2010.1501.

54. Dai C-T, Chang Y-K, Huang C-J, Hung T-M. Exercise mode and executive function in older adults: an ERP study of task-switching. Brain Cogn. 2013;83:153-62. https://doi.org/10.1016/j.bandc.2013.07.007.

55. Zhu H, Chen A, Guo W, Zhu F, Wang B. Which type of exercise is more beneficial for cognitive function? A meta-analysis of the effects of open-skill exercise versus closed-skill exercise among children, adults, and elderly populations. Appl Sci. 2020;10:2737. https://doi.org/10. 3390/app10082737.

56. Hung C-L, Tseng J-W, Chao H-H, Hung T-M, Wang H-S. Effect of acute exercise mode on serum brain-derived neurotrophic factor (BDNF) and task switching performance. J Clin Med. 2018. https://doi.org/10.3390/ jcm7100301.

57. Frey I, Berg A, Gratwohl D, Keul J. Freiburger fragebogen zur körperlichen Aktivität—Entwicklung, Prüfung und Anwendung. Soz Präventivmed. 1999. https://doi.org/10.1007/BF01667127.

58. Folstein MF, Folstein SE, McHugh PR. Mini-mental state. J Psychiatr Res. 1975;12:189-98. https://doi.org/10.1016/0022-3956(75)90026-6.

59. Robergs RA, Landwehr R. The surprising history of the " $H R_{\max }=220-$ age" equation. J Exer Physiol. 2002;5:1-10.

60. Karvonen MJ, Kentala E, Mustala O. The effects of training on heart rate; a longitudinal study. Ann Med Exp Biol Fenn. 1957;35:307-15.

61. Borg G. Perceived exertion as an indicator of somatic stress. Scand J Rehabil Med. 1970;2:92-8.

62. Noble BJ, Borg GA, Jacobs I, Ceci R, Kaiser P. A category-ratio perceived exertion scale: relationship to blood and muscle lactates and heart rate. Med Sci Sport Exerc. 1983;15:523-8.

63. Armstrong RA. When to use the Bonferroni correction. Ophthalmic Physiol Opt. 2014;34:502-8. https://doi.org/10.1111/opo.12131.

64. Lakens D. Calculating and reporting effect sizes to facilitate cumulative science: a practical primer for t-tests and ANOVAs. Front Psychol. 2013;4:863. https://doi.org/10.3389/fpsyg.2013.00863.

65. Cabral DF, Rice J, Morris TP, Rundek T, Pascual-Leone A, Gomes-Osman J. Exercise for brain health: an investigation into the underlying mechanisms guided by dose. Neurotherapeutics. 2019. https://doi.org/10. 1007/s13311-019-00749-w.

66. Erickson Kl, Prakash RS, Voss MW, Chaddock L, Heo S, McLaren M, et al. Brain-derived neurotrophic factor is associated with age-related decline in hippocampal volume. J Neurosci. 2010;30:5368-75. https://doi.org/ 10.1523/JNEUROSCI.6251-09.2010.

67. Gubbi S, Quipildor GF, Barzilai N, Huffman DM, Milman S. 40 years of IGF1: IGF1: the Jekyll and Hyde of the aging brain. J Mol Endocrinol. 2018;61:T171-85. https://doi.org/10.1530/JME-18-0093.

68. Ferris LT, Williams JS, Shen C-L. The effect of acute exercise on serum brain-derived neurotrophic factor levels and cognitive function. Med 
Sci Sport Exerc. 2007;39:728-34. https://doi.org/10.1249/mss.0b013 e31802f04c7.

69. Griffin ÉW, Mullally S, Foley C, Warmington SA, O'Mara SM, Kelly AM. Aerobic exercise improves hippocampal function and increases BDNF in the serum of young adult males. Physiol Behav. 2011;104:934-41. https://doi.org/10.1016/j.physbeh.2011.06.005.

70. Tonoli C, Heyman E, Buyse L, Roelands B, Piacentini MF, Bailey S, et al. Neurotrophins and cognitive functions in T1D compared with healthy controls: effects of a high-intensity exercise. Appl Physiol Nutr Metab. 2015;40:20-7. https://doi.org/10.1139/apnm-2014-0098.

71. Gmiąt A, Jaworska J, Micielska K, Kortas J, Prusik K, Lipowski M, et al. Improvement of cognitive functions in response to a regular Nordic walking training in elderly women - a change dependent on the training experience. Exp Gerontol. 2018;104:105-12. https://doi.org/10. 1016/j.exger.2018.02.006.

72. Dinoff A, Herrmann N, Swardfager W, Lanctôt KL. The effect of acute exercise on blood concentrations of brain-derived neurotrophic factor in healthy adults: a meta-analysis. Eur J Neurosci. 2017;46:1635-46. https://doi.org/10.1111/ejn.13603.

73. Marston KJ, Newton MJ, Brown BM, Rainey-Smith SR, Bird S, Martins RN, Peiffer JJ. Intense resistance exercise increases peripheral brain-derived neurotrophic factor. J Sci Med Sport. 2017;20:899-903. https://doi.org/ 10.1016/j.jsams.2017.03.015.

74. Nakahashi T, Fujimura H, Altar CA, Li J, Kambayashi J-I, Tandon NN, Sun B. Vascular endothelial cells synthesize and secrete brain-derived neurotrophic factor. FEBS Lett. 2000;470:113-7. https://doi.org/10.1016/ S0014-5793(00)01302-8

75. Matthews VB, Åström M-B, Chan MHS, Bruce CR, Krabbe KS, Prelovsek $\mathrm{O}$, et al. Erratum to: brain-derived neurotrophic factor is produced by skeletal muscle cells in response to contraction and enhances fat oxidation via activation of AMP-activated protein kinase. Diabetologia. 2012;55:864. https://doi.org/10.1007/s00125-011-2406-z.

76. Das KP, Chao SL, White LD, Haines WT, Harry GJ, Tilson HA, Barone S. Differential patterns of nerve growth factor, brain-derived neurotrophic factor and neurotrophin-3 mRNA and protein levels in developing regions of rat brain. Neuroscience. 2001;103:739-61. https://doi.org/10. 1016/S0306-4522(01)00011-2

77. Conner JM, Lauterborn JC, Yan Q, Gall CM, Varon S. Distribution of brainderived neurotrophic factor (BDNF) protein and mRNA in the normal adult rat CNS: evidence for anterograde axonal transport. J Neurosci. 1997;17:2295-313. https://doi.org/10.1523/JNEUROSCl.17-07-02295. 1997.

78. Klein AB, Williamson R, Santini MA, Clemmensen C, Ettrup A, Rios M, et al. Blood BDNF concentrations reflect brain-tissue BDNF levels across species. Int J Neuropsychopharmacol. 2011;14:347-53. https://doi.org/ 10.1017/S1461145710000738

79. Pan W, Banks WA, Fasold MB, Bluth J, Kastin AJ. Transport of brainderived neurotrophic factor across the blood-brain barrier. Neuropharmacology. 1998;37:1553-61. https://doi.org/10.1016/S0028-3908(98) 00141-5.

80. Rasmussen P, Brassard P, Adser H, Pedersen MV, Leick L, Hart E, et al. Evidence for a release of brain-derived neurotrophic factor from the brain during exercise. Exp Physiol. 2009;94:1062-9. https://doi.org/10. 1113/expphysiol.2009.048512.

81. Szuhany KL, Bugatti M, Otto MW. A meta-analytic review of the effects of exercise on brain-derived neurotrophic factor. J Psychiatr Res. 2015;60:56-64. https://doi.org/10.1016/j.jpsychires.2014.10.003.

82. Enette L, Vogel T, Fanon JL, Lang PO. Effect of interval and continuous aerobic training on basal serum and plasma brain-derived neurotrophic factor values in seniors: a systematic review of intervention studies. Rejuvenation Res. 2017;20:473-83. https://doi.org/10.1089/rej.2016. 1886

83. Forti LN, van Roie E, Njemini R, Coudyzer W, Beyer I, Delecluse C, Bautmans I. Dose-and gender-specific effects of resistance training on circulating levels of brain derived neurotrophic factor (BDNF) in community-dwelling older adults. Exp Gerontol. 2015;70:144-9. https:// doi.org/10.1016/j.exger.2015.08.004.

84. Ferris LT, Williams JS, Shen C-L. The effect of acute exercise on serum brain-derived neurotrophic factor levels and cognitive function. Med Sci Sport Exerc. 2007;39:728-34. https://doi.org/10.1249/mss.0b013 e31802f04c7.
85. Netz Y. Is there a preferred mode of exercise for cognition enhancement in older age? -a narrative review. Front Med. 2019;6:57. https:// doi.org/10.3389/fmed.2019.00057.

86. Pesce C. Shifting the focus from quantitative to qualitative exercise characteristics in exercise and cognition research. J Sport Exerc Psychol. 2012;34:766-86. https://doi.org/10.1123/jsep.34.6.766.

87. Tsai C-L, Pan C-Y, Chen F-C, Tseng Y-T. Open- and closed-skill exercise interventions produce different neurocognitive effects on executive functions in the elderly: a 6-month randomized. Control Trial Front Aging Neurosci. 2017;9:294. https://doi.org/10.3389/fnagi.2017.00294.

88. Cabello Manrique D, González-Badillo JJ. Analysis of the characteristics of competitive badminton. Br J Sport Med. 2003;37:62-6. https://doi. org/10.1136/bjsm.37.1.62.

89. Faude $\mathrm{O}$, Meyer T, Rosenberger F, Fries M, Huber G, Kindermann W. Physiological characteristics of badminton match play. Eur J Appl Physiol. 2007;100:479-85. https://doi.org/10.1007/s00421-007-0441-8.

90. Phomsoupha M, Laffaye $\mathrm{G}$. The science of badminton: game characteristics, anthropometry, physiology, visual fitness and biomechanics. Sport Med. 2015;45:473-95. https://doi.org/10.1007/ s40279-014-0287-2.

91. Kurdi FN, Flora R. Physical exercise increased brain-derived neurotrophic factor in elderly population with depression. Open Access Maced J Med Sci. 2019;7:2057-61. https://doi.org/10.3889/oamjms.2019.574.

92. Laske C, Banschbach S, Stransky E, Bosch S, Straten G, Machann J, et al. Exercise-induced normalization of decreased BDNF serum concentration in elderly women with remitted major depression. Int J Neuropsychopharmacol. 2010;13:595-602. https://doi.org/10.1017/S146114570 9991234.

93. Yu H, Chen Z-Y. The role of BDNF in depression on the basis of its location in the neural circuitry. Acta Pharmacol Sin. 2011;32:3-11. https:// doi.org/10.1038/aps.2010.184.

94. Duman RS, Monteggia LM. A neurotrophic model for stress-related mood disorders. Biol Psychiatry. 2006;59:1116-27. https://doi.org/10. 1016/j.biopsych.2006.02.013.

95. Müller P, Rehfeld K, Schmicker M, Hökelmann A, Dordevic M, Lessmann $V$, et al. Evolution of neuroplasticity in response to physical activity in old age: the case for dancing. Front Aging Neurosci. 2017;9:56. https:// doi.org/10.3389/fnagi.2017.00056.

96. Erickson KI, Voss MW, Prakash RS, Basak C, Szabo A, Chaddock L, et al. Exercise training increases size of hippocampus and improves memory. Proc Natl Acad Sci USA. 2011;108:3017-22. https://doi.org/10.1073/ pnas.1015950108.

97. Zoladz JA, Pilc A, Majerczak J, Grandys M, Zapart-Bukowska J, Duda $K$. Endurance training increases plasma brain-derived neurotrophic factor concentration in young healthy men. J Physiol Pharmacol. 2008;59(Suppl 7):119-32.

98. Nofuji Y, Suwa M, Sasaki H, Ichimiya A, Nishichi R, Kumagai S. Different circulating brain-derived neurotrophic factor responses to acute exercise between physically active and sedentary subjects. J Sport Sci Med. 2012;11:83-8.

99. Máderová D, Krumpolec P, Slobodová L, Schön M, Tirpáková V, Kovaničová Z, et al. Acute and regular exercise distinctly modulate serum, plasma and skeletal muscle BDNF in the elderly. Neuropeptides. 2019;78: 101961. https://doi.org/10.1016/j.npep.2019.101961.

100. Correia PR, Pansani A, Machado F, Andrade M, da Silva AC, Scorza FA, et al. Acute strength exercise and the involvement of small or large muscle mass on plasma brain-derived neurotrophic factor levels. Clinics. 2010;65:1123-6. https://doi.org/10.1590/S1807-593220100011000 12.

101. Cho H-C, Kim J, Kim S, Son YH, Lee N, Jung SH. The concentrations of serum, plasma and platelet BDNF are all increased by treadmill $\mathrm{VO}_{2 \max }$ performance in healthy college men. Neurosci Lett. 2012;519:78-83. https://doi.org/10.1016/j.neulet.2012.05.025.

102. Cappon J, Brasel JA, Mohan S, Cooper DM. Effect of brief exercise on circulating insulin-like growth factor I. J Appl Physiol. 1994;76:2490-6. https://doi.org/10.1152/jappl.1994.76.6.2490.

103. Lee IH, Seo EJ, Lim IS. Effects of aquatic exercise and CES treatment on the changes of cognitive function, BDNF, IGF-1, and VEGF of persons with intellectual disabilities. J Exerc Nutrition Biochem. 2014;18:19-24. https://doi.org/10.5717/jenb.2014.18.1.19. 
104. Berg U, Bang P. Exercise and circulating insulin-like growth factor I. Horm Res. 2004;62(Suppl 1):50-8. https://doi.org/10.1159/000080759.

105. Tsai C-L, Wang C-H, Pan C-Y, Chen F-C, Huang T-H, Chou F-Y. Executive function and endocrinological responses to acute resistance exercise. Front Behav Neurosci. 2014;8:1-12. https://doi.org/10.3389/fnbeh.2014. 00262.

106. Tsai C-L, Wang C-H, Pan C-Y, Chen F-C. The effects of long-term resistance exercise on the relationship between neurocognitive performance and GH, IGF-1, and homocysteine levels in the elderly. Front Behav Neurosci. 2015;9:1-12. https://doi.org/10.3389/fnbeh.2015. 00023.

107. Cassilhas RC, Viana VAR, Grassmann V, Santos RT, Santos RF, Tufik S, Mello MT. The impact of resistance exercise on the cognitive function of the elderly. Med Sci Sport Exerc. 2007:39:1401-7. https://doi.org/10.1249/ mss.0b013e318060111f

108. Marston KJ, Brown BM, Rainey-Smith SR, Peiffer JJ. Resistance exerciseinduced responses in physiological factors linked with cognitive health. J Alzheimer's Dis. 2019;68:39-64. https://doi.org/10.3233/JAD-181079.

109. Picillo M, Pivonello R, Santangelo G, Pivonello C, Savastano R, Auriemma $R$, et al. Serum IGF-1 is associated with cognitive functions in early, drug-naïve Parkinson's disease. PLoS ONE. 2017;12: e0186508. https:// doi.org/10.1371/journal.pone.0186508.

110. Niblock MM, Brunso-Bechtold JK, Riddle DR. Insulin-like growth factor I stimulates dendritic growth in primary somatosensory cortex. J Neurosci Off J Soc Neurosci. 2000;20:4165-76.

111. Bazgir B, Delpasand A, Shirvani H. Serum levels of interleukin-6 (IL-6), $\mathrm{LL}-10$, and lactate in response to combat physical fitness test. Sport Sci Health. 2019;16:911. https://doi.org/10.1007/s11332-019-00567-9.

112. Febbraio MA, Pedersen BK. Muscle-derived interleukin-6: mechanisms for activation and possible biological roles. FASEB J. 2002;16:1335-47. https://doi.org/10.1096/fi.01-0876rev.

113. Pedersen BK, Steensberg A, Fischer C, Keller C, Keller P, Plomgaard P, et al. The metabolic role of IL-6 produced during exercise: is IL-6 an exercise factor? Proc Nutr Soc. 2004;63:263-7. https://doi.org/10.1079/ PNS2004338.

114. Nybo L, Nielsen B, Pedersen BK, Møller K, Secher NH. Interleukin-6 release from the human brain during prolonged exercise. J Physiol. 2002:542:991-5. https://doi.org/10.1113/jphysiol.2002.022285.

115. Pedersen BK, Febbraio M. Muscle-derived interleukin-6-a possible link between skeletal muscle, adipose tissue, liver, and brain. Brain Behav Immun. 2005;19:371-6. https://doi.org/10.1016/j.bbi.2005.04.008.

116. Funk JA, Gohlke J, Kraft AD, MCPherson CA, Collins JB, Jean HG. Voluntary exercise protects hippocampal neurons from trimethyltin injury: possible role of interleukin- 6 to modulate tumor necrosis factor receptor-mediated neurotoxicity. Brain Behav Immun. 2011;25:1063-77. https://doi.org/10.1016/j.bbi.2011.03.012.

117. Fischer CP. Interleukin- 6 in acute exercise and training: what is the biological relevance? Exerc Immunol Rev. 2006;12:6-33.

118. de Coelho FGM, Gobbi S, Andreatto CAA, Corazza DI, Pedroso RV, Santos-Galduróz RF. Physical exercise modulates peripheral levels of brain-derived neurotrophic factor (BDNF): a systematic review of experimental studies in the elderly. Arch Gerontol Geriatr. 2013;56:10-5. https://doi.org/10.1016/jarchger201206.003.

119. Huang T, Larsen KT, Ried-Larsen M, Møller NC, Andersen LB. The effects of physical activity and exercise on brain-derived neurotrophic factor in healthy humans: a review. Scand J Med Sci Sport. 2014;24:1-10. https:// doi.org/10.1111/sms.12069.

120. Matura S, Fleckenstein J, Deichmann R, EngeroffT, Füzéki E, Hattingen $\mathrm{E}$, et al. Effects of aerobic exercise on brain metabolism and grey matter volume in older adults: results of the randomised controlled SMART trial. Transl Psychiatry. 2017;7: e1172. https://doi.org/10.1038/tp.2017. 135.

121. Forti LN, Njemini R, Beyer I, Eelbode E, Meeusen R, Mets T, Bautmans I. Strength training reduces circulating interleukin-6 but not brainderived neurotrophic factor in community-dwelling elderly individuals. Age. 2014:36:9704. https://doi.org/10.1007/s11357-014-9704-6.

122. Kim J-H, Kim D-Y. Aquarobic exercises improve the serum blood irisin and brain-derived neurotrophic factor levels in elderly women. Exp Gerontol. 2018;104:60-5. https://doi.org/10.1016/j.exger.2018.01.024.

123. Coelho FM, Pereira DS, Lustosa LP, Silva JP, Dias JMD, Dias RCD, et al. Physical therapy intervention (PTI) increases plasma brain-derived neurotrophic factor (BDNF) levels in non-frail and pre-frail elderly women. Arch Gerontol Geriatr. 2012;54:415-20. https://doi.org/10. 1016/j.archger.2011.05.014.

124. Bos I, De Boever P, Vanparijs J, Pattyn N, Panis LI, Meeusen R. Subclinical effects of aerobic training in urban envirement. Med Sci Sport Exerc. 2013;45:439-47.

125. Swift DL, Johannsen NM, Myers VH, Earnest CP, Smits JAJ, Blair SN, Church TS. The effect of exercise training modality on serum brain derived neurotrophic factor levels in individuals with type 2 diabetes. PLoS ONE. 2012. https://doi.org/10.1371/journal.pone.0042785.

126. Grégoire C-A, Berryman N, St-Onge F, Vu TTM, Bosquet L, Arbour N, Bherer L. Gross motor skills training leads to increased brain-derived neurotrophic factor levels in healthy older adults: a pilot study. Front Physiol. 2019;10:410. https://doi.org/10.3389/fphys.2019.00410.

127. Rehfeld K, Lüders A, Hökelmann A, Lessmann V, Kaufmann J, Brigadski T, et al. Dance training is superior to repetitive physical exercise in inducing brain plasticity in the elderly. PLOS ONE. 2018. https://doi.org/10. 1371/journal.pone.0196636.

128. Rehfeld K, Müller P, Aye N, Schmicker M, Dordevic M, Kaufmann J, et al. Dancing or fitness sport? The effects of two training programs on hippocampal plasticity and balance abilities in healthy seniors. Front Hum Neurosci. 2017;11:305. https://doi.org/10.3389/fnhum.2017.00305.

129. Bekinschtein P, Oomen CA, Saksida LM, Bussey TJ. Effects of environmental enrichment and voluntary exercise on neurogenesis, learning and memory, and pattern separation: BDNF as a critical variable? Semin Cell Dev Biol. 2011;22:536-42. https://doi.org/10.1016/j.semcdb.2011. 07.002

130. Schiffer T, Schulte S, Hollmann W, Bloch W, Strüder HK. Effects of strength and endurance training on brain-derived neurotrophic factor and insulin-like growth factor 1 in humans. Horm Metab Res. 2009:41:250-4. https://doi.org/10.1055/s-0028-1093322.

131. Voss MW, Erickson KI, Prakash RS, Chaddock L, Kim JS, Alves H, et al. Neurobiological markers of exercise-related brain plasticity in older adults. Brain Behav Immun. 2013;28:90-9. https://doi.org/10.1016/j.bbi. 2012.10.021.

132. Elmlinger MW, Kühnel W, Weber MM, Ranke MB. Reference ranges for two automated chemiluminescent assays for serum insulin-like growth factor I (IGF-I) and IGF-binding protein 3 (IGFBP-3). Clin Chem Lab Med. 2004. https://doi.org/10.1515/CCLM.2004.112.

133. Velesso CP. Regulation of muscle mass by growth hormone and IGF-I. Br J Pharmacol. 2008. https://doi.org/10.1038/bjp.2008.171.

134. Cassilhas RC, Viana VAR, Grassmann V, Santos RT, Santos RF, Tufik S, Mello MT. The impact of resistance exercise on the cognitive function of the elderly. Med Sci Sport Exerc. 2007;39:1401-7. https://doi.org/10.1249/ mss.0b013e318060111f.

135. Baker LD, Frank LL, Foster-Schubert K, Green PS, Wilkinson CW, McTiernan $A$, et al. Effects of aerobic exercise on mild cognitive impairment: a controlled trial. Arch Neurol. 2010;67:71-9. https://doi.org/10.1001/ archneurol.2009.307.

136. Bautmans I, Njemini R, Vasseur S, Chabert H, Moens L, Demanet C, Mets T. Biochemical changes in response to intensive resistance exercise training in the elderly. Gerontology. 2005;51:253-65. https://doi.org/10. $1159 / 000085122$

137. Phillips MD, Flynn MG, McFarlin BK, Stewart LK, Timmerman KL. Resistance training at eight-repetition maximum reduces the inflammatory milieu in elderly women. Med Sci Sport Exerc. 2010;42:314-25. https:// doi.org/10.1249/MSS.0b013e3181b11ab7.

138. Bradburn S, Sarginson J, Murgatroyd CA. Association of peripheral interleukin-6 with global cognitive decline in non-demented adults: a meta-analysis of prospective studies. Front Aging Neurosci. 2017;9:438. https://doi.org/10.3389/fnagi.2017.00438.

139. Pedersen BK, Febbraio MA. Muscle as an endocrine organ: focus on muscle-derived interleukin-6. Physiol Rev. 2008;88:1379-406. https:// doi.org/10.1152/physrev.90100.2007.

140. Pedersen BK, Febbraio M. Exercise and interleukin-6 action. Expert Rev Endocrinol Metab. 2006;1:319-21. https://doi.org/10.1586/17446651.1. 3.319.

141. Smart NA, Larsen Al, Le Maitre JP, Ferraz AS. Effect of exercise training on interleukin-6, tumour necrosis factor alpha and functional capacity in heart failure. Cardiol Res Pract. 2011. https://doi.org/10.4061/2011/ 532620. 
142. Raison CL, Knight JM, Pariante C. Interleukin (IL)-6: a good kid hanging out with bad friends (and why sauna is good for health). Brain Behav Immun. 2018;73:1-2. https://doi.org/10.1016/j.bbi.2018.06.008.

143. Ellingsgaard $H$, Hojman P, Pedersen BK. Exercise and health—emerging roles of IL-6. Curr Opin Physio. 2019;10:49-54. https://doi.org/10.1016/j. cophys.2019.03.009.

144. Patterson S, Pattison J, Legg H, Gibson A-M, Brown N. The impact of badminton on health markers in untrained females. J Sport Sci. 2017;35:1098-106. https://doi.org/10.1080/02640414.2016.1210819.

145. Garber CE, Blissmer B, Deschenes MR, Franklin BA, Lamonte MJ, Lee I-M, et al. American College of Sports Medicine position stand. Quantity and quality of exercise for developing and maintaining cardiorespiratory, musculoskeletal, and neuromotor fitness in apparently healthy adults: guidance for prescribing exercise. Med Sci Sport Exerc. 2011;43:133459. https://doi.org/10.1249/MSS.0b013e318213fefb.

\section{Publisher's Note}

Springer Nature remains neutral with regard to jurisdictional claims in published maps and institutional affiliations.

- fast, convenient online submission

- thorough peer review by experienced researchers in your field

- rapid publication on acceptance

- support for research data, including large and complex data types

- gold Open Access which fosters wider collaboration and increased citations

- maximum visibility for your research: over $100 \mathrm{M}$ website views per year

At BMC, research is always in progress.

Learn more biomedcentral.com/submissions 